\title{
Lógica fuzzy aplicada ao pré-tratamento do capim-elefante: uma revisão
}

\section{bibliográfica sistemática}

\author{
Fuzzy logic applied to elephant grass pretreatment: a systematic bibliographic review \\ Lógica difusa aplicada al pretratamiento de pasto elefante: una revisión sistemática de la literatura
}

Recebido: 14/11/2021 | Revisado: 19/11/2021 | Aceito: 19/11/2021 | Publicado: 29/11/2021

\author{
Emmanuel Zullo Godinho \\ ORCID: https://orcid.org/0000-0001-5281-6608 \\ Universidade Estadual Paulista, Brasil \\ E-mail: emmanuel.godinho@unesp.br \\ Fernando de Lima Caneppele \\ ORCID: https://orcid.org/0000-0003-4498-8682 \\ Universidade de São Paulo, Brasil \\ E-mail: caneppele@usp.br
}

\begin{abstract}
Resumo
A economia global é diretamente dependente dos combustíveis fósseis, consumindo um total de aproximadamente 70\% destas fontes de energia. Contudo, as energias renováveis, principalmente os biocombustíveis produzidos pela biomassa estão ganhando espaço, com destaque para o capim-elefante, que vem se destacando na produção de bioetanol no Brasil. No entanto, antes de ocorrer a fermentação para a produção do bioetanol, a biomassa deverá passar por um processo chamado de pré-tratamento. Por isso, quando se analisa os processos químicos, a otimização nas variáveis para o prétratamento é fundamental, assim surge a necessidade de aplicar um sistema de modelagem matemática como a lógica nebulosa ou fuzzy. Diante desse contexto, o objetivo desse artigo é identificar como está configurado o estado do conhecimento sobre a aplicação da lógica fuzzy no pré-tratamento alcalino no capim-elefante. Com a realização da pesquisa utilizando a Revisão Bibliográfica Sistêmica (RBS), foi possível identificar diversas oportunidades da aplicação da lógica fuzzy nos pré-tratamentos alcalinos no capim-elefante. Dos 86 documentos analisados nesta pesquisa, $100 \%$ foram de artigos de pesquisa e de revisão bibliográfica, o que demonstra uma relevância na academia ao uso do capim-elefante na produção bioetanol e, da mesma forma, que as pesquisas sobre a aplicação de pré-tratamento nas biomassas vem ganhando importância nos últimos anos, sendo cada vez mais estudada e desenvolvida por pesquisadores da área. Apesar de não apresentar nenhum artigo com referência específica da utilização da lógica fuzzy no pré-tratamento alcalino do capim-elefante, isso abre um grande leque para novas pesquisas utilizando a lógica nebulosa.
\end{abstract}

Palavras-chave: Sustentabilidade; Lógica difusa; Pennisetum purpureum; $\mathrm{NaOH}$.

\begin{abstract}
The global economy is directly dependent on fossil fuels, consuming a total of approximately $70 \%$ of these energy sources. However, renewable energies, especially biofuels produced by biomass, are gaining ground, with emphasis on elephant grass, which has been standing out in the production of bioethanol in Brazil. However, before fermentation takes place for the production of bioethanol, the biomass must undergo a process called pre-treatment. Therefore, when analyzing the chemical processes, the optimization of the variables for the pre-treatment is essential, thus the need to apply a mathematical modeling system such as fuzzy or fuzzy logic arises. Given this context, the objective of this article is to identify how the state of knowledge about the application of fuzzy logic in the alkaline pre-treatment of elephant grass is configured. By conducting the research using the Systemic Literature Review (RBS), it was possible to identify several opportunities for the application of fuzzy logic in alkaline pre-treatments in elephant grass. Of the 86 documents analyzed in this research, $100 \%$ were from research and bibliographic review articles, which demonstrates the relevance in academia of the use of elephant grass in the production of bioethanol and, in the same way, research on the application of pre- Biomass treatment has gained importance in recent years, being increasingly studied and developed by researchers in the area. Although it does not present any article with specific reference to the use of fuzzy logic in the alkaline pre-treatment of elephant grass, this opens up a wide range for further research using fuzzy logic.
\end{abstract}

Keywords: Sustainability; Fuzzy logic; Pennisetum purpureum; $\mathrm{NaOH}$.

\section{Resumen}

La economía mundial depende directamente de los combustibles fósiles, consumiendo un total de aproximadamente el $70 \%$ de estas fuentes de energía. Sin embargo, las energías renovables, especialmente los biocombustibles producidos por biomasa, están ganando terreno, con énfasis en el pasto elefante, que se ha destacado en la producción de bioetanol en Brasil. Sin embargo, antes de que tenga lugar la fermentación para la producción de bioetanol, la biomasa debe 
someterse a un proceso llamado pretratamiento. Por tanto, a la hora de analizar los procesos químicos, la optimización de las variables para el pretratamiento es fundamental, por lo que surge la necesidad de aplicar un sistema de modelado matemático como la lógica difusa o nebulosa. Ante este contexto, el objetivo de este artículo es identificar cómo se configura el estado de conocimiento sobre la aplicación de la lógica difusa en el pretratamiento alcalino de pasto elefante. Al realizar la investigación utilizando Systemic Literature Review (RBS), fue posible identificar varias oportunidades para la aplicación de lógica difusa en pretratamientos alcalinos en pasto elefante. De los 86 documentos analizados en esta investigación, el $100 \%$ provienen de artículos de investigación y revisión bibliográfica, lo que demuestra la relevancia en la academia del uso de pasto elefante en la producción de bioetanol y, de igual forma, la investigación sobre la aplicación de pre El tratamiento con biomasa ha ganado importancia en los últimos años, siendo cada vez más estudiado y desarrollado por investigadores del área. Aunque no presenta ningún artículo con referencia específica al uso de la lógica difusa en el pretratamiento alcalino de la hierba elefante, esto abre un amplio rango para futuras investigaciones utilizando la lógica difusa.

Palabras clave: Sustentabilidad; Lógica difusa; Pennisetum purpureum; $\mathrm{NaOH}$.

\section{Introdução}

A economia global é diretamente dependente dos combustíveis fósseis (carvão, petróleo e gás), consumindo um total de aproximadamente $70 \%$ destas fontes para o uso de energia (Ahmad et al., 2018). Uma das matérias-primas utilizadas é o petróleo, que é o precursor de diversos produtos, além da produção de combustíveis (Saidur et al., 2011). Por ser um recurso considerado não renovável, ou seja, produzido em um longo tempo (acima de 100 anos), pode vir a ser escasso nos próximos anos (Gunaseelan, 1997).

Segundo o National Oceanic and Atmospheric Administration que publicou seu relatório anual em 2019 sobre o uso de combustíveis fósseis e, apresentou resultados que mostram que gases que considerados prejudiciais a camada de ozônio estão sendo liberados em um volume superior ao desejado para que não venha causar problemas no meio ambiente (GODINHO et al., 2019). Menegol et al. (2014) relatam que a emissão de gases considerados prejudiciais ao meio ambiente estão acima de 400 ppm, comparando com a revolução industrial, estes valores estavam entre 180 a 280 ppm. Uma solução para que estes valores sejam reduzidos é o aumento no uso de fontes renováveis. Por isso, existe a necessidade de pesquisar sobre novas fontes energéticas, principalmente renováveis, e uma opção viável são os biocombustíveis (Gutierrez et al., 2016).

Segundo dados do Ministério de Minas e Energia (MME) do Brasil, órgão responsável pela publicação do Balanço Energético Nacional (BEN), em 2019 apresentou dados de produção energética a partir de biomassa entre 17\% do total da matriz energética geral nacional, sendo considerada a segunda principal fonte de energia, superada apenas pelo petróleo e seus derivados (MME, 2020).

Uma fonte importante para a produção de energia limpa é a biomassa, por possuir uma grande oferta dentro das cadeias produtivas (Aditiya et al., 2016). Nesta linha, muitas são as biomassas que podem ser utilizadas como o bagaço da cana-deaçúcar, as palhas e as cascas provenientes de grãos como milho, o trigo, a soja, o capim-elefante, dentre outros (Edem Cudjoe Bensah et al., 2015). Esses resíduos são formados por 40 a 50\% de celulose, sendo o principal componente para a produção do etanol segunda geração (Singh \& Dhepe, 2016).

Dentro das matérias-primas citadas anteriormente, o capim-elefante tem se destacado, pois além de suas características de uso alimentar animal, possui grande massa de folhas e sua facilidade desde o plantio a colheita (A. M. H. Rocha et al., 2017).

Segundo (Fontoura et al., 2015), o capim-elefante tem como nome cientifico Pennisetum purpureum pertencente à família da Graminee. É uma espécie de clima tropical que apresenta metabolismo do tipo C4 e possui uma característica de produtividade aproximada de 45 toneladas de massa seca por hectare ao ano, enquanto a cana-de-açúcar e o milho produz aproximadamente 21 ton ha-1 entre açúcar e bagaço e 13 ton ha-1 (grãos e fogões), respectivamente (Paula et al., 2020).

Rocha et al., 2017 realça que o capim-elefante é considerado uma gramínea com alta eficiência no âmbito de volume de biomassa vegetal, em relação as plantas de mesmas espécies, tendo um rendimento de até $84 \%$ maior que a cana-de-açúcar e $37 \%$ superior que o eucalipto. 
Diversas são as aplicações energéticas do capim-elefante, com grande destaque para a produção de bioetanol, além da combustão direta, da gaseificação, do carvoejamento (processo de conversão termoquímica sem presença de oxigênio) (A. M. H. Rocha et al., 2017) (Blois et al., 2017).

Para que possa ser produzido o bioetanol, a biomassa passa por alguns processos na indústria como a lavagem, prétratamento e fermentação com leveduras, entretanto o processo de maior importância é o pré-tratamento, pois possui diversas finalidades, dentre elas: a remoção da lignina e consequentemente o aumento da área superficial onde deixará a celulose mais exposta facilitando o processo de digestão enzimática (Timilsena et al., 2013).

Os pré-tratamentos podem ser classificados em ácidos, alcalinos, explosão a vapor e etc. (Dutra et al., 2018). O prétratamento que tem mostrado alta eficiência na deslignificação é o alcalino com a aplicação do hidróxido de sódio NaOH (Kim et al., 2016b).

O mecanismo de pré-tratamento alcalino é baseado na saponificação intermolecular das ligações cruzadas de ésteres da xilana, que estão presentes na hemicelulose juntamente com outros componentes, como a exemplo, lignina e hemicelulose (Minmunin et al., 2015).

Karagöz et al. (2012) ressaltam que deve existir um modelo específico de pré-tratamento para cada biomassa, ou até mesmo podendo utilizar o mesmo pré-tratamento, mas, com alterações em seus processos químicos. Estas metodologias devem resultar em altas taxas de rendimentos de açúcares fermentescíveis, apresentando baixo custo final com menor redução de resíduos gerados para a produção do bioetanol (Yasuda et al., 2012) \& (Gomes et al., 2013).

Neste sentido, o processo de otimização é importante para que se possa encontrar qual o melhor, ou os melhores, pontos para melhorar o processo produtivo e uma ferramenta que aplica bem estes conceitos é a lógica fuzzy (Nassef et al., 2019).

Datado de 1965, Lofti Zadeh, divulgou para a comunidade acadêmica o artigo Fuzzy Sets, onde explanou sobre o conceito de fuzzificação, o que atribuiu desde então como o "pai" da lógica fuzzy (Lucas, 2011).

A lógica fuzzy possui em seu sistema alguns conceitos que se entende por "conceitos vagos", que nada mais é que dados que não possui limites, tais como: muito, alto e jovem (Furlong et al., 2019). Sendo que, os sistemas computacionais trabalham com uma lógica chamada bivalente ou booleana, que em alguns casos pode ser imprecisa (Vasconcelos de Almeida Sá \& Chiun Wen, 2019).

Por essa razão, a lógica fuzzy se destaca perante estes modelos computacionais, pois transforma dados linguísticos em dados numéricos, trabalhando com as habilidades humanas como conversar, raciocinar e tomar decisões (Bracarense et al., 2013).

Diante desse contexto, o objetivo desse artigo é identificar como está configurado o estado do conhecimento sobre a aplicação da lógica fuzzy no pré-tratamento alcalino no capim-elefante.

\section{Metodologia}

Considerando o problema da pesquisa apresentada "sobre a aplicação da lógica fuzzy no pré-tratamento alcalino no capim-elefante", que, segundo indicado por (Cai et al., 2020) este enunciado interrogativo argumenta sobre a importância da aplicação do pré-tratamento nas biomassas para a produção de energias renováveis. Então, segundo orientações dos mesmos autores, foi construída a hipótese de que é possível otimizar a aplicação do pré-tratamento no capim-elefante por meios de dados existentes em forma de uma revisão bibliográfica como sendo o verdadeiro "fator produtivo" da pesquisa.

A técnica de pesquisa adotada para este artigo, que segundo (Maranzato \& Salerno, 2018), foi a de prospecção de documentos com bases de artigos científicos. Esta técnica considera que o autor deva "possuir olhar crítico" para separar os dados detalhes relevantes dos triviais, fazendo anotações organizadas e utilizando métodos rigorosos para validar suas observações (Massi et al., 2019).

Assim, devido a estas considerações dos autores (Coelho et al., 2021) e (Eusébio \& João, 2020), adotou-se a Revisão 
Bibliográfica Sistemática (RBS) como base metodológica para a realização do presente estudo.

A RBS é um método onde se mapeia trabalhos científicos publicados em bases especificas sobre determinado tema de pesquisa, específico, que adota procedimentos, etapas e ferramentas técnicas para criação de uma síntese do conhecimento existente sobre o tema de interesse (Galvão et al., 2004).

Por utilizar uma estrutura metódica, a RBS requer uma pergunta clara sobre o assunto e, com isso é definido uma estratégia de busca e de critérios para inclusão ou exclusão e leitura de documentos aplicando critérios rigorosos em cada item selecionado (Aquino et al., 2020).

Para atender o objetivo desse artigo, foi utilizada uma RBS, adotando-se o método desenvolvido por (Conforto et al., 2011), que é composto por três fases: Entrada, Processamento e Saída.

A fase de entrada é definida com o problema da pesquisa que a RBS visa responder, onde delimita-se os objetivos, juntamente com os critérios para inclusão e exclusão dos documentos no determinado estudo e, principalmente a criação das Strings de busca. Na sequência, a fase de processamento, são realizadas as buscas, a seleção inicial dos documentos por meio de leitura e análise. Por fim, a fase de saída, os documentos são cadastrados e baixados com intuito de facilitar as análises, os processamentos para que se possa elaborar a síntese dos resultados obtidos.

\subsection{Entrada}

O problema ao qual essa pesquisa busca responder é: Como está configurado o estado do conhecimento sobre a aplicação do uso da lógica fuzzy no pré-tratamento do capim-elefante?

Dessa forma, o objetivo da presente RBS é a identificação do estado do conhecimento das ferramentas da aplicação da lógica fuzzy no pré-tratamento do capim-elefante com hidróxido de sódio.

A escolha das bases de dados deu-se de acordo com a sua relevância na área de estudo, sendo estas: ScienceDirect, Scopus, Web Of Science, Scielo e SpringerLink.

Após um levantamento inicial de palavras-chave e, criação das Strings de busca, limitou-se a um total de 11 Strings, para a primeira busca exploratória, apresentados na Tabela 1, pesquisa realizada no dia 15 fevereiro de 2021.

Tabela 1. Testes para definição dos Strings de busca.

\begin{tabular}{|c|c|c|c|c|c|c|}
\hline Id & Strings & ScienceDirect & Scopus & Web of Science & Scielo & SpringerLink \\
\hline 1 & (Agriculture) & 1.118 .037 & 348.382 & 1.331 .095 & 6.909 & 752.048 \\
\hline 2 & (Elephant grass) & 5.887 & 123.484 & 1.836 & 465 & 7.311 \\
\hline 3 & (Pennisetum purpureum) & 1.724 & 2.134 & 2.7447 & 393 & 1.821 \\
\hline 4 & (Second-generation ethanol) & 133 & 4.324 & 1.357 & 13 & 606.657 \\
\hline 5 & (Biofuels) & 77.943 & 43.265 & 100.657 & 388 & 40.333 \\
\hline 6 & (Pretreatments) & 530.077 & 125.874 & 342.627 & 863 & 210.320 \\
\hline 8 & (Lignin) & 109.819 & 72.290 & 100.604 & 1.103 & 65.358 \\
\hline 9 & (Cellulosic) & 460.412 & 25.840 & 40.189 & 922 & 24.393 \\
\hline 10 & (Lignocellulosic biomass) & 33.781 & 401.193 & 487.087 & 3.282 & 285.920 \\
\hline 11 & (Fuzzy logic) & 71.262 & 94.725 & 78.813 & 358 & 90.965 \\
\hline & Total & 2.409 .148 & 1.305 .730 & 2.613.517 & 15.399 & 2.375 .363 \\
\hline
\end{tabular}

Fonte: Dados da pesquisa (fevereiro, 2021).

Os Strings de busca foram elaborados com base nos termos de interesse, onde foram realizados testes iniciais para determinação do String que melhor atenderia aos objetivos da pesquisa, como pode-se observar no Quadro 1, sendo elegidos os Strings: (Agriculture) AND ((Elephant grass) OR (Pennisetum purpureum)) AND (Second generation ethanol); (Agriculture) AND ((Elephant grass) OR (Pennisetum purpureum)) AND ((Biofuels) OR (Pretreatments) OR (Sodium hidroxide)); (Agriculture) AND ((Elephant grass) OR (Pennisetum purpureum)) AND ((Lignin) OR (Cellulose) OR (Lignocellulosic 
biomass)) e (Agriculture) AND ((Elephant grass) OR (Pennisetum purpureum)) AND (Fuzzy logic), (pesquisa realizada no dia 15 de fevereiro de 2021).

Quadro 1. Testes para definição dos Strings de busca.

\begin{tabular}{|c|c|c|c|c|c|}
\hline \multirow[b]{2}{*}{ Strings de busca } & \multicolumn{5}{|c|}{ Bases de dados } \\
\hline & ScienceDirect & Scopus & $\begin{array}{l}\text { Web of } \\
\text { Science }\end{array}$ & Scielo & SpringerLink \\
\hline $\begin{array}{l}\text { (Agriculture) AND ((Elephant grass) OR (Pennisetum purpureum)) AND (Second } \\
\text { generation ethanol) }\end{array}$ & 1 & 0 & 0 & 0 & 0 \\
\hline $\begin{array}{l}\text { (Agriculture) AND ((Elephant grass) OR (Pennisetum purpureum)) AND } \\
\text { ((Biofuels) OR (Pretreatments) OR (Sodium hidroxide)) }\end{array}$ & 683 & 12 & 2 & 0 & 387 \\
\hline $\begin{array}{l}\text { (Agriculture) AND ((Elephant grass) OR (Pennisetum purpureum }) \text { ) AND } \\
\text { ((Lignin) OR (Cellulose) OR (Lignocellulosic biomass)) }\end{array}$ & 1066 & 10 & 4 & 1 & 596 \\
\hline $\begin{array}{l}\text { (Agriculture) AND ((Elephant grass) OR (Pennisetum purpureum)) AND (Fuzzy } \\
\text { logic) }\end{array}$ & 43 & 0 & 0 & 0 & 53 \\
\hline Total & 1793 & 22 & 6 & 1 & 1036 \\
\hline
\end{tabular}

Fonte: Dados da pesquisa (fevereiro, 2021).

Este Quadro 1, exibe as Strings que foram elencadas para a busca e a conformação das frases de filtros com os devidos conectivos para que o software possa varrer a rede e os respectivos bancos de dados das bases científicas, apresentando os resultados obtidos de cada um dos filtros.

No primeiro momento, optou-se por delimitar a pesquisa em três filtros: Filtro 1 - Rejeitar todos os tipos de documento, exceto artigos completos e artigos de revisão, ambos publicados em revistas científicas; Filtro 2 - Rejeitar todos os documentos que não estivessem no idioma de interesse (português ou em inglês) e, Filtro 3 - Delimitado o lapso temporal (2000 a 2020 vinte anos).

O Quadro 2, apresenta a quantidade de artigos com a inclusão dos filtros citados.

Quadro 2. Testes para definição dos Strings de busca.

\begin{tabular}{|c|c|c|c|c|c|}
\hline \multirow[b]{2}{*}{ Strings de busca } & \multicolumn{5}{|c|}{ Bases de dados } \\
\hline & ScienceDirect & Scopus & $\begin{array}{l}\text { Web of } \\
\text { Science }\end{array}$ & Scielo & SpringerLink \\
\hline $\begin{array}{l}\text { (Agriculture) AND ((Elephant grass) OR (Pennisetum } \\
\text { purpureum)) AND (Second generation ethanol) }\end{array}$ & 1 & 0 & 0 & 0 & 0 \\
\hline $\begin{array}{l}\text { (Agriculture) AND ((elephant grass) OR (Pennisetum } \\
\text { purpureum)) AND ((Biofuels) OR (Pretreatments) OR (Sodium } \\
\text { hidroxide)) }\end{array}$ & 304 & 8 & 2 & 0 & 147 \\
\hline $\begin{array}{l}\text { (Agriculture) AND ((Elephant grass) OR (Pennisetum } \\
\text { purpureum)) AND ((Lignin) OR (Cellulosic) OR (Lignocellulosic } \\
\text { biomass)) }\end{array}$ & 540 & 7 & 4 & 1 & 235 \\
\hline $\begin{array}{l}\text { (Agriculture) AND ((Elephant grass) OR (Pennisetum } \\
\text { purpureum)) AND (Fuzzy logic) }\end{array}$ & 5 & 0 & 0 & 0 & 1 \\
\hline Total & 850 & 15 & 6 & 1 & 383 \\
\hline
\end{tabular}

Fonte: Dados da pesquisa (fevereiro, 2021).

Como pode-se observar no Quadro 2, o número de artigos nas bases Science Direct e na SpringerLink estavam acima do esperado. Com isso, foi elaborado novamente um correlação tridimensional das principais palavras-chave proveniente do tema, sendo Agriculture, Elephant grass e Pennisetum purpureum com as demais Strings, conforme o Quadro 3. 
Quadro 3. Testes para definição dos Strings de busca.

\begin{tabular}{|c|c|c|}
\hline Strings de busca & ScienceDirect & SpringerLink \\
\hline $\begin{array}{l}\text { (Agriculture) AND ((Elephant grass) OR (Pennisetum purpureum)) AND (Second generation } \\
\text { ethanol) AND ((Biofuels) OR (Pretreatments) OR (Sodium hidroxide)) }\end{array}$ & 1 & 0 \\
\hline $\begin{array}{l}\text { (Agriculture) AND ((Elephant grass) OR (Pennisetum purpureum)) AND (Second generation } \\
\text { ethanol) AND ((Lignin) OR (Cellulose) OR (Lignocellulosic biomass)) }\end{array}$ & 1 & 0 \\
\hline $\begin{array}{l}\text { (Agriculture) AND ((Elephant grass) OR (Pennisetum purpureum)) AND (Second generation } \\
\text { ethanol) AND (Fuzzy logic) }\end{array}$ & 0 & 0 \\
\hline $\begin{array}{l}\text { (Agriculture) AND ((Elephant grass) OR (Pennisetum purpureum)) AND ((Biofuels) OR } \\
\text { (Pretreatments) OR (Sodium hidroxide)) AND ((Lignin) OR (Cellulose) OR (Lignocellulosic } \\
\text { biomass)) }\end{array}$ & 529 & 207 \\
\hline $\begin{array}{l}\text { (Agriculture) AND ((Elephant grass) OR (Pennisetum purpureum)) AND ((Biofuels) OR } \\
\text { (Pretreatments) OR (Sodium hidroxide)) AND (Fuzzy logic) }\end{array}$ & 22 & 5 \\
\hline $\begin{array}{l}\text { (Agriculture) AND ((Elephant grass) OR (Pennisetum purpureum)) AND ((Lignin) OR (Cellulosic) } \\
\text { OR (Lignocellulosic biomass)) AND (Fuzzy logic) }\end{array}$ & 26 & 0 \\
\hline Total & 579 & 212 \\
\hline
\end{tabular}

Fonte: Dados da pesquisa (fevereiro, 2021).

\section{Resultados e Discussão}

\subsection{Processamento}

Com os documentos previamente selecionados, e com base nos critérios da fase inicial (Entrada), iniciou-se a etapa de processamento, na qual foram exportados 813 documentos das bases de dados e, importados para o Software de gerenciamento Mendeley ${ }^{\circledR}$, sendo: 579 documentos da Science Direct, 15 da Scopus, 6 Web Of Science, 1 da Scielo e 212 da SpringerLink, como pode-se observar na Figura 1.

Figura 1. Publicações por ano.

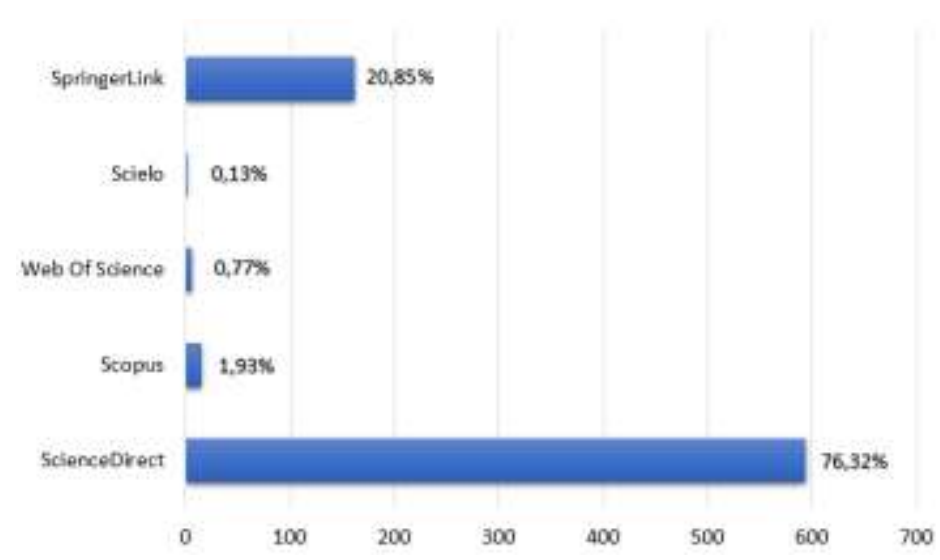

Fonte: Dados da pesquisa (fevereiro, 2021).

A Figura 1, que apresenta os resultados do software Mendeley®, traz informações em formato de gráfico de pizza, separando os percentuais relativos a quantidade de documentos obtidos de cada uma das bases prospectadas.

A partir de então, foram realizadas rejeições por tipo de documento (artigo de pesquisa ou revisão de literatura) (filtro 1). No filtro 2, a seleção foi definir documentos nos idiomas inglês e no português, e posterior, estar fora da linha do tempo de 2000 a 2020, isto no filtro 3, conforme apresentado no Quadro 4. 
Quadro 4. Testes para definição dos Strings de busca.

\begin{tabular}{|c|c|c|c|c|c|c|}
\hline \multicolumn{6}{|c|}{ Mendeley® - Fase de Seleção } & \multirow{2}{*}{ Total de Documentos } \\
\hline Base de Dados & Science Direct & Scopus & Web of Science & Scielo & SpringerLink & \\
\hline Inicial & 579 & 22 & 6 & 1 & 212 & 820 \\
\hline Filtro 1 & 240 & 4 & 0 & 0 & 124 & \\
\hline Filtro 2 & 1 & 2 & 0 & 0 & 1 & \\
\hline Filtro 3 & 43 & 1 & 0 & 0 & 9 & \\
\hline Doc rejeitados & 284 & 7 & 0 & 0 & 134 & 425 \\
\hline Final & 295 & 15 & 6 & 1 & 78 & 395 \\
\hline
\end{tabular}

Fonte: Dados da pesquisa (fevereiro, 2021).

Na sequência foram aplicados mais 5 filtros, sendo: filtro 1 - duplicados identificados pelo Mendeley®, filtro 2 duplicados identificados manualmente, filtro 3 - rejeitados na análise textual simples, filtro 4 - indisponíveis para acesso na integra e filtro 5 rejeitados na análise textual detalhada, conforme o Quadro 5.

Quadro 5. Testes para definição dos Strings de busca.

\begin{tabular}{|c|c|c|c|c|c|c|}
\hline \multicolumn{6}{|c|}{ Mendeley® - Fase de Seleção } & \multirow{2}{*}{ Total de Documentos } \\
\hline Base de Dados & Science Direct & Scopus & Web of Science & Scielo & SpringerLink & \\
\hline Filtro 1 & 62 & 0 & 0 & 0 & 0 & 62 \\
\hline Filtro 2 & 0 & 0 & 0 & 0 & 0 & 0 \\
\hline Filtro 3 & 138 & 7 & 6 & 1 & 11 & 163 \\
\hline Filtro 4 & 0 & 0 & 0 & 0 & 51 & 51 \\
\hline Filtro 5 & 32 & 0 & 0 & 0 & 1 & 33 \\
\hline Final & 232 & 7 & 6 & 1 & 63 & 309 \\
\hline
\end{tabular}

Fonte: Dados da pesquisa (fevereiro, 2021).

Por fim, após todas as análises realizadas e com as aplicações dos filtros estabelecidos, as bases científicas (ScienceDirect, Scopus, Web Of Science, Scielo e SpringerLink), resultaram em 63; 8; 0; 0 e 15 artigos respectivamente, que seriam analisados para a pesquisa.

\subsection{Saída}

Foram baixados, então, os 86 documentos como listado no Quadro 6, sendo que, todos foram lidos na íntegra e tabulados de forma a apresentar os resultados obtidos.

Quadro 6. Testes para definição dos Strings de busca.

\begin{tabular}{|c|c|c|c|}
\hline $\mathbf{N}$. & Autor & Título & Contribuiç̧ão \\
\hline 1 & $\begin{array}{l}\text { (Charlton et al., } \\
\text { 2009) }\end{array}$ & $\begin{array}{c}\text { The biorefining opportunities in Wales: } \\
\text { Understanding the scope for building a } \\
\text { sustainable, biorenewable economy using plant } \\
\text { biomass }\end{array}$ & Artigo apresentando as oportunidades no mercado para uma biorrefinaria \\
\hline 2 & (Sánchez, 2009) & $\begin{array}{l}\text { Lignocellulosic residues: Biodegradation and } \\
\text { bioconversion by fungi }\end{array}$ & $\begin{array}{c}\text { Artigo com grande importância da aplicação de fungos para a } \\
\text { deslignificação da biomassa, pois os mesmos podem oxidar e degradar } \\
\text { polissacarídeos. }\end{array}$ \\
\hline 3 & $\begin{array}{c}\text { (Varfolomeev et al., } \\
\text { 2009) }\end{array}$ & $\begin{array}{c}\text { Energy Carriers from Renewable Sources: } \\
\text { Chemical Aspects }\end{array}$ & $\begin{array}{l}\text { Um trabalho que apresenta uma visão global sobre a importância do uso } \\
\text { de energias renováveis }\end{array}$ \\
\hline 4 & (Demain, 2009) & Biosolutions to the energy problem & $\begin{array}{l}\text { Artigo importante que deixa claro que o mercado mundial necessita e } \\
\text { pode trabalhar em grande escala com energias renováveis principalmente } \\
\text { com microorganismos na produção de energia provinda de material } \\
\text { reciclado }\end{array}$ \\
\hline 5 & $\begin{array}{l}\text { (Chandel et al., } \\
\text { 2010) }\end{array}$ & $\begin{array}{l}\text { Key drivers infl uencing the commercialization } \\
\text { of ethanol-based biorefineries }\end{array}$ & $\begin{array}{l}\text { Artigo importante que apresenta vários pontos sobre uma perspectiva tão } \\
\text { importante para a produção de bioetanol de materiais agrícolas, onde } \\
\text { neste modelo deve aplicar o pré-tratamento como fonte para quebra das } \\
\text { estruturas lignocelulósicas. }\end{array}$ \\
\hline 6 & $\begin{array}{l}\text { (Abbasi \& Abbasi, } \\
\text { 2010) }\end{array}$ & $\begin{array}{l}\text { Biomass energy and the environmental impacts } \\
\text { associated with its production and utilization }\end{array}$ & $\begin{array}{c}\text { O artigo faz um balanço das várias fontes de biomassa e das possíveis } \\
\text { maneiras pelas quais ela pode ser utilizada para gerar energia, } \\
\text { examinando principalmente as questões ambientais. }\end{array}$ \\
\hline
\end{tabular}




\begin{tabular}{|c|c|c|c|}
\hline 7 & (Saidur et al., 2011) & A review on biomass as a fuel for boilers & $\begin{array}{l}\text { O artigo transcreve sobre as mudanças climáticas e a perspectiva de } \\
\text { mudança de uso de energias renováveis, como a biomassa que é uma das } \\
\text { primeiras fontes de energia com propriedades muito específicas. }\end{array}$ \\
\hline 8 & $\begin{array}{l}\text { (Takara \& Khanal, } \\
\text { 2011) }\end{array}$ & $\begin{array}{l}\text { Green processing of tropical banagrass into } \\
\text { biofuel and biobased products: An innovative } \\
\text { biorefinery approach }\end{array}$ & $\begin{array}{c}\text { Artigo apresentando as melhores características de cultivo e uso do } \\
\text { capim-elefante seria um corte com aproximadamente } 4 \text { meses e que este } \\
\text { pode ser utilizado desde o caule rente ao solo como as folhas, onde ele } \\
\text { utilizou um pré-tratamento com ácido sulfúrico para o processo de } \\
\text { deslignificação. }\end{array}$ \\
\hline 9 & (Duku et al., 2011) & $\begin{array}{l}\text { A comprehensive review of biomass resources } \\
\text { and biofuels potential in Ghana }\end{array}$ & $\begin{array}{c}\text { Artigo descreve a contribuição da produção de energia provinda da } \\
\text { biomassa em Gana, mas que o grande problema são as pesquisas, mas } \\
\text { mesmo assim ainda tem um grande potencial de crescimento do uso de } \\
\text { energia provindo desta base. }\end{array}$ \\
\hline 10 & (Xie et al., 2011) & $\begin{array}{l}\text { Dynamic changes of lignin contents of MT-1 } \\
\text { elephant grass and its closely related cultivars }\end{array}$ & $\begin{array}{l}\text { Artigo importante sobre } 5 \text { cultivares de capim-elefante, onde os autores } \\
\text { analisaram a constituição química em diferentes estágios para saber a } \% \\
\text { de lignina. }\end{array}$ \\
\hline 11 & (Yasuda et al., 2012) & $\begin{array}{l}\text { Ethanol production from non-pretreated } \\
\text { napiergrass through a simultaneous } \\
\text { saccharification and fermentation process } \\
\text { followed by a pentose fermentation with } \\
\text { Escherichia coli KO11 }\end{array}$ & $\begin{array}{l}\text { Artigo sobre produção de bioetanol de capim-elefante utilizando } \\
\text { Escherichia coli KO11. Obtendo bons resultados finais. }\end{array}$ \\
\hline 12 & (Ho et al., 2012) & $\begin{array}{l}\text { Development of cellulosic ethanol production } \\
\text { process via co-culturing of artificial } \\
\text { cellulosomal Bacillus and kefir yeast }\end{array}$ & $\begin{array}{c}\text { Artigo que combina dois microorganismos em um processo fermentativo, } \\
\text { sendo Bacillus e outras combinações para saber a melhor resposta para a } \\
\text { produção de açúcares redutíveis. }\end{array}$ \\
\hline 13 & (Puri et al., 2012) & $\begin{array}{l}\text { Biofuel production: Prospects, challenges and } \\
\text { feedstock in Australia }\end{array}$ & $\begin{array}{l}\text { Artigo sobre o uso de energia provinda de recursos fosseis, ainda são os } \\
\text { mais utilizados na Austrália, mas a produção de biocombustíveis está na } \\
\text { rota do governo nacional com a aplicação de tecnologias industriais. }\end{array}$ \\
\hline 14 & (Plácido et al., 2013) & $\begin{array}{l}\text { Evaluation of ligninolytic enzymes, } \\
\text { ultrasonication and liquid hot water as } \\
\text { pretreatments for bioethanol production from } \\
\text { cotton gin trash }\end{array}$ & $\begin{array}{c}\text { Artigo sobre a aplicação de } 3 \text { pré-tratamentos diferentes e que o melhor } \\
\text { foi a combinação da ultrassônica com a água quente para a produção de } \\
\text { bioetanol de algodão }\end{array}$ \\
\hline 15 & (Ohimain, 2013) & $\begin{array}{c}\text { A review of the Nigerian biofuel policy and } \\
\text { incentives (2007) }\end{array}$ & $\begin{array}{l}\text { Artigo apresenta claramente os incentivos e as políticas de aplicação do } \\
\text { uso de energias renováveis na Nigéria, o pode emperrar são os conflitos } \\
\text { entre povos e o governo. }\end{array}$ \\
\hline 16 & (Smith et al., 2013) & $\begin{array}{l}\text { Second generation biofuels and bioinvasions: } \\
\text { An evaluation of invasive risks and policy } \\
\text { responses in the United States and Canada }\end{array}$ & $\begin{array}{c}\text { O artigo de revisão coloca que os governos americanos e canadenses } \\
\text { devam aplicar políticas forte para aumentar o uso de energias renováveis } \\
\text { em seus países. }\end{array}$ \\
\hline 17 & (Wu et al., 2013) & $\begin{array}{l}\text { Application of new expansion pretreatment } \\
\text { method on agricultural waste. Part I: Influence } \\
\text { of pretreatment on the properties of lignin }\end{array}$ & $\begin{array}{l}\text { Artigo apresentando resultados da eficiência do uso de pré-tratamentos } \\
\text { para remoção ou desestruturação da lignina em biomassa de arroz. }\end{array}$ \\
\hline 18 & (Lima et al., 2014) & $\begin{array}{l}\text { Evaluating the composition and processing } \\
\text { potential of novel sources of Brazilian biomass } \\
\text { for sustainable biorenewables production }\end{array}$ & $\begin{array}{c}\text { Artigo de pesquisa comparando diversos materiais lignocelulósicos para } \\
\text { produção de biocombustíveis }\end{array}$ \\
\hline 19 & $\begin{array}{l}\text { (Carvalho-Netto et } \\
\text { al., 2014) }\end{array}$ & $\begin{array}{l}\text { The potential of the energy cane as the main } \\
\text { biomass crop for the cellulosic industry }\end{array}$ & $\begin{array}{l}\text { Artigo sobre os benefícios do uso da cana como fonte de energia } \\
\text { utilizando as biomassas para a indústria celulósica }\end{array}$ \\
\hline 20 & (Yasuda et al., 2014) & $\begin{array}{c}\text { Bio-ethanol production through simultaneous } \\
\text { saccharification and co-fermentation (SSCF) of } \\
\text { a low-moisture anhydrous ammonia (LMAA)- } \\
\text { pretreated napiegrass (Pennisetum purpureum } \\
\text { Schumach) } \\
\end{array}$ & $\begin{array}{c}\text { Artigo o qual os autores comprovaram a alta eficiência na produção de } \\
\text { bioetanol a partir da biomassa de CE, utilizando alguns fungos para } \\
\text { fermentação. }\end{array}$ \\
\hline 21 & (Perlatti et al., 2014) & $\begin{array}{l}\text { Green chemistry, sustainable agriculture and } \\
\text { processing systems: a Brazilian overview }\end{array}$ & $\begin{array}{l}\text { Esta revisão discute os desenvolvimentos tecnológicos atuais e } \\
\text { incipientes para o uso da biomassa para gerar produtos químicos de base } \\
\text { biológica na última década, com foco nos conceitos de Química Verde } \\
\text { para modelos sustentáveis de agricultura e processamento no Brasil }\end{array}$ \\
\hline 22 & (Knoll et al., 2014) & $\begin{array}{c}\text { Harvest Management of' Tifton 85' } \\
\text { Bermudagrass for Cellulosic Ethanol } \\
\text { Production } \\
\end{array}$ & Artigo esclarece sobre as aplicações da biotecnologia utilizando o CE \\
\hline 23 & (Daher et al., 2014) & $\begin{array}{c}\text { Use of elephant grass for energy production in } \\
\text { Campos dos Goytacazes-RJ, Brazil } \\
\end{array}$ & $\begin{array}{c}\text { Artigo onde avaliou vários cultivares de CE onde avaliou-se as } \\
\text { constituições químicas na região do RJ }\end{array}$ \\
\hline 24 & $\begin{array}{l}\text { (Cardona et al., } \\
\text { 2014) }\end{array}$ & $\begin{array}{l}\text { Effects of the pretreatment method on } \\
\text { enzymatic hydrolysis and ethanol } \\
\text { fermentability of the cellulosic fraction from } \\
\text { elephant grass }\end{array}$ & $\begin{array}{c}\text { Artigo de pesquisa que apresentou respostas importantes da aplicação do } \\
\text { pré-tratamento alcalino para a deslignificação da biomassa para a } \\
\text { produção de bioetanol }\end{array}$ \\
\hline 25 & $\begin{array}{c}\text { (López-Bellido et al., } \\
\text { 2014) }\end{array}$ & $\begin{array}{c}\text { Energy crops: Prospects in the context of } \\
\text { sustainable agriculture }\end{array}$ & $\begin{array}{c}\text { Artigo de revisão apresentando a eficiência de avaliar a porcentagem de } \\
\text { celulose e lignina para a produção de bioetanol }\end{array}$ \\
\hline 26 & $\begin{array}{l}\text { (Antonopoulou et al., } \\
\text { 2015) }\end{array}$ & $\begin{array}{c}\text { The Effect of Aqueous Ammonia Soaking } \\
\text { Pretreatment on Methane Generation Using } \\
\text { Different Lignocellulosic Biomasses }\end{array}$ & $\begin{array}{l}\text { Artigo descreve sobre o uso de pré-tratamento aquoso, onde solubilizou a } \\
\text { hemicelulose e removeu parte da celulose }\end{array}$ \\
\hline 27 & $\begin{array}{c}\text { (Edem Cudjoe } \\
\text { Bensah et al., 2015) }\end{array}$ & $\begin{array}{c}\text { African perspective on cellulosic ethanol } \\
\text { production }\end{array}$ & $\begin{array}{c}\text { Artigo de revisão que apresenta um avanço na produção de bioetanol na } \\
\text { África, mas que emperra nos custos das aplicaçoses das enzimas }\end{array}$ \\
\hline
\end{tabular}




\begin{tabular}{|c|c|c|c|}
\hline 28 & (del Río et al., 2015) & $\begin{array}{l}\text { Differences in the chemical structure of the } \\
\text { lignins from sugarcane bagasse and straw }\end{array}$ & $\begin{array}{l}\text { Artigo explicando sobre as composições da lignina, como o } \\
\text { conhecimento e a aplicação dos pré-tratamentos podem interferir nos } \\
\text { resultados da deslignificação do bagaço da cana }\end{array}$ \\
\hline 29 & $\begin{array}{l}\text { (Puspawati et al., } \\
\text { 2015) }\end{array}$ & $\begin{array}{l}\text { The Production of Bioethanol Fermentation } \\
\text { Substrate from Eucheuma cottonii Seaweed } \\
\text { through Hydrolysis by Cellulose Enzyme }\end{array}$ & $\begin{array}{l}\text { Artigo de pesquisa que apresenta sobre a Eucheuma cottonii, que é capaz } \\
\text { de ser usado como substrato de fermentação de bioetanol na forma de } \\
\text { açúcares de redução por hidrólise enzimática usando enzimas de celulose }\end{array}$ \\
\hline 30 & $\begin{array}{l}\text { (Gupta \& Verma, } \\
\quad 2015)\end{array}$ & $\begin{array}{l}\text { Sustainable bio-ethanol production from agro- } \\
\text { residues: A review }\end{array}$ & $\begin{array}{l}\text { Artigo de revisão que apresenta resultados sobre a conversão da celulose } \\
\text { para o etanol onde requer novas tecnologias de pré-tratamento, } \\
\text { enzimática e fermentação, para tornar todo o processo econômico }\end{array}$ \\
\hline 31 & (Scholl et al., 2015a) & $\begin{array}{c}\text { Elephant grass (Pennisetum purpureum } \\
\text { Schum.) pretreated via steam explosion as a } \\
\text { carbon source for cellulases and xylanases in } \\
\text { submerged cultivation }\end{array}$ & $\begin{array}{l}\text { O artigo apresentou resultados que indicaram que o CE pré-tratado, } \\
\text { usando explosão de vapor, pode ser usado como substrato para a } \\
\text { produção de enzimas para a hidrólise da biomassa lignocelulósica }\end{array}$ \\
\hline 32 & $\begin{array}{l}\text { (Fontoura et al., } \\
\text { 2015) }\end{array}$ & $\begin{array}{c}\text { Elephant grass biorefineries: towards a cleaner } \\
\text { Brazilian energy matrix? }\end{array}$ & $\begin{array}{c}\text { Artigo de revisão onde o mesmo apresenta valores para o investimento } \\
\text { em energia limpa, além disso, as estratégias da Biorefinarias foram } \\
\text { positivas, o que indica que as mesmas utilizam o esquema de } \\
\text { comercialização proposto neste estudo, representando também uma } \\
\text { oportunidade viável e interessante para uma diversificação sustentável da } \\
\text { matriz energética } \\
\end{array}$ \\
\hline 33 & (Jin et al., 2015) & $\begin{array}{l}\text { High-pressure homogenization pretreatment of } \\
\text { four different lignocellulosic biomass for } \\
\text { enhancing enzymatic digestibility }\end{array}$ & $\begin{array}{c}\text { O artigo utilizou o pré-tratamento de HPH em diversas biomassas, o } \\
\text { melhor resultado na deslignificação foi utilizando o CE, com isso } \\
\text { comprovou que o pré-tratamento do HPH pode aumentar a produção de } \\
\text { biocombustíveis em uma condição leve sem adicionar quaisquer produtos } \\
\text { químicos }\end{array}$ \\
\hline 34 & (Scholl et al., 2015b) & $\begin{array}{c}\text { Ethanol production from sugars obtained } \\
\text { during enzymatic hydrolysis of elephant grass } \\
\text { (Pennisetum purpureum, Schum.) pretreated by } \\
\text { steam explosion } \\
\end{array}$ & $\begin{array}{l}\text { Artigo apresentou dados de maior produção de bioetanol de CE onde o } \\
\text { mesmo foi pré-tratado com vapor d'água quente, onde o mesmo gerou } \\
\text { uma grande quantidade de compostos inibitórios solúveis em água para } \\
\text { hidrólise e fermentação }\end{array}$ \\
\hline 35 & (Wen et al., 2015) & $\begin{array}{c}\text { Comparison and evaluation of concurrent } \\
\text { saccharification and anaerobic digestion of } \\
\text { Napier grass after pretreatment by three } \\
\text { microbial consortia }\end{array}$ & $\begin{array}{l}\text { Artigo onde foi aplicado o CE para a produção de biometano com a } \\
\text { aplicação de três modelos de pré-tratamentos mais eficazes }\end{array}$ \\
\hline 36 & $\begin{array}{l}\text { (Takara \& Khanal, } \\
\quad \text { 2015) }\end{array}$ & $\begin{array}{l}\text { Characterizing compositional changes of } \\
\text { Napier grass at different stages of growth for } \\
\text { biofuel and biobased products potential }\end{array}$ & $\begin{array}{l}\text { Artigo sugeriu que o teor de celulose não muda significativamente em } \\
\text { relação à idade }\end{array}$ \\
\hline 37 & (Rambo et al., 2015) & $\begin{array}{l}\text { Analysis of the lignocellulosic components of } \\
\text { biomass residues for biorefinery opportunities }\end{array}$ & $\begin{array}{c}\mathrm{O} \text { artigo trabalhou com plantas diferenciadas para a produção o processo } \\
\text { geral de produçãoo do bioetanol, com grande eficácia para o açaí }\end{array}$ \\
\hline 38 & $\begin{array}{l}\text { (Surendra \& Khanal, } \\
\text { 2015) }\end{array}$ & $\begin{array}{c}\text { Effects of crop maturity and size reduction on } \\
\text { digestibility and methane yield of dedicated } \\
\text { energy crop }\end{array}$ & $\begin{array}{l}\mathrm{O} \text { artigo coloca que a biomassa do CE apresentou a maior digestibilidade } \\
\text { de celulose e hemicelulose quando seu corte foi aos } 6 \text { meses, enquanto a } \\
\text { digestibilidade de celulose-perda e hemicelulose foram as mais baixas } \\
\text { para a biomassa colhida aos } 8 \text { meses de maturação. }\end{array}$ \\
\hline 39 & (Ullah et al., 2015) & $\begin{array}{c}\text { Assessing the lignocellulosic biomass resources } \\
\text { potential in developing countries: A critical } \\
\text { review }\end{array}$ & $\begin{array}{c}\text { Artigo de revisão que apresenta os impactos e as viabilidades econômicas } \\
\text { dos países para a produção de energias renováveis a partir de ligninas de } \\
\text { biomassas }\end{array}$ \\
\hline 40 & (Ji \& Long, 2016) & $\begin{array}{c}\text { A review of the ecological and socioeconomic } \\
\text { effects of biofuel and energy policy } \\
\text { recommendations }\end{array}$ & $\begin{array}{c}\text { Artigo de revisão que apresenta dados sobre as políticas de } \\
\text { incrementação de energias renováveis nos países, frisando que os custos } \\
\text { são os maiores empecilhos, além do uso inadequado dos mesmos }\end{array}$ \\
\hline 41 & $\begin{array}{l}\text { (Abdelaziz et al., } \\
\text { 2016) }\end{array}$ & $\begin{array}{l}\text { Biological valorization of lowmolecular weight } \\
\text { lignin }\end{array}$ & $\begin{array}{c}\text { Artigo de revisão sobre as fontes de lignina, os métodos de } \\
\text { deslignificação, os caminhos biológicos para conversão das subpartículas } \\
\text { de lignina e as ferramentas analíticas necessárias para caracterizar e } \\
\text { avaliar os principais atributos de lignina }\end{array}$ \\
\hline 42 & (Zabed et al., 2016) & $\begin{array}{c}\text { Fuel ethanol production from lignocellulosic } \\
\text { biomass: An overview on feedstocks and } \\
\text { technological approaches } \\
\end{array}$ & $\begin{array}{l}\text { Artigo de revisão que apresenta uma visão geral sobre a diversidade de } \\
\text { biomassa, as abordagens tecnológicas e contribuição microbiana para a } \\
\text { conversão da lignina em Bioetanol }\end{array}$ \\
\hline 43 & (Ren et al., 2016) & $\begin{array}{c}\text { A review on bioconversion of lignocellulosic } \\
\text { biomass to H2: Key challenges and new } \\
\text { insights }\end{array}$ & $\begin{array}{l}\text { Artigo de revisão apresentando sobre as possibilidades de produção } \\
\text { hidrogênio onde correlacionou os bioprocessos envolvidos, juntamente } \\
\text { com os desafios e novos insights sobre a produção de biohidrogênio } \\
\text { lignocelulósico }\end{array}$ \\
\hline 44 & $\begin{array}{l}\text { (Rabemanolontsoa \& } \\
\quad \text { Saka, 2016) }\end{array}$ & Various pretreatments of lignocellulosics & $\begin{array}{c}\text { Artigo de revisão onde apresenta um histórico do pré-tratamento em } \\
\text { biomassas, juntamente com as conversões químicas, físico-químicas e } \\
\text { bioquímicas }\end{array}$ \\
\hline 45 & (Kim et al., 2016a) & $\begin{array}{l}\text { A review on alkaline pretreatment technology } \\
\text { for bioconversion of lignocellulosic biomass }\end{array}$ & $\begin{array}{l}\text { Artigo de revisão, onde é apresentada as principais tecnologias alcalinas } \\
\text { de pré-tratamento com intuito de mudar as estruturas químicas e físicas } \\
\text { da biomassa }\end{array}$ \\
\hline 46 & $\begin{array}{l}\text { (Phitsuwan et al., } \\
\text { 2015) }\end{array}$ & $\begin{array}{l}\text { Structural changes and enzymatic response of } \\
\text { Napier grass (Pennisetum purpureum) stem } \\
\text { induced by alkaline pretreatment }\end{array}$ & $\begin{array}{c}\text { Artigo apresentando resultados com aplicação de pré-tratamentos } \\
\text { alcalinos no CE, sendo } \mathrm{NaOH}, \mathrm{Ca}(\mathrm{OH})_{2}, \mathrm{NH}_{3}, \text { e } \mathrm{H}_{2} \mathrm{O}_{2}\left(\mathrm{aH}_{2} \mathrm{O}_{2}\right) \text { com } \\
\text { melhor resultado } \mathrm{NaOH}\end{array}$ \\
\hline 47 & (Coffin et al., 2016) & $\begin{array}{l}\text { Potential for Production of Perennial Biofuel } \\
\text { Feedstocks in Conservation Buffers on the } \\
\text { Coastal Plain of Georgia, USA } \\
\end{array}$ & $\begin{array}{l}\text { Artigo de revisão que apresenta estimativas sobre a produção de } \\
\text { biocombustíveis nas Planícies da Costa Oeste do Estado da Geórgia USA }\end{array}$ \\
\hline 48 & $\begin{array}{l}\text { (Johansson \& } \\
\text { Rydberg, 2017) }\end{array}$ & $\begin{array}{l}\text { Is an increased use of biofuels the road to } \\
\text { sustainability? }\end{array}$ & $\begin{array}{c}\text { Artigo de revisão sobre o avanço das áreas com culturas para produção } \\
\text { de biocombustíveis }\end{array}$ \\
\hline 49 & (He et al., 2017) & $\begin{array}{l}\text { Lignocellulosic butanol production from } \\
\text { Napier grass using semi-simultaneous } \\
\text { saccharification fermentation }\end{array}$ & $\begin{array}{l}\text { Artigo de pesquisa que apresenta resultados do CE com pré-tratamento } \\
\qquad \mathrm{NaOH} \text { e } \mathrm{H}_{2} \mathrm{SO}_{4}\end{array}$ \\
\hline
\end{tabular}




\begin{tabular}{|c|c|c|c|}
\hline 50 & $\begin{array}{l}\text { (Manisha \& Yadav, } \\
\text { 2017) }\end{array}$ & $\begin{array}{c}\text { Technological advances and applications of } \\
\text { hydrolytic enzymes for valorization of } \\
\text { lignocellulosic biomass }\end{array}$ & $\begin{array}{l}\text { Artigo de revisão onde é relatado a importância da aplicação de enzimas } \\
\text { na fermentação de biomassa lignocelulósica }\end{array}$ \\
\hline 51 & $\begin{array}{l}\text { (Mohapatra et al., } \\
\text { 2017) }\end{array}$ & $\begin{array}{l}\text { Application of pretreatment, fermentation and } \\
\text { molecular techniques for enhancing bioethanol } \\
\text { production from grass biomass - A review }\end{array}$ & $\begin{array}{l}\text { Artigo de revisão sobre a importância da aplicação de técnicas } \\
\text { moleculares para a produção de bioetanol }\end{array}$ \\
\hline 52 & $\begin{array}{l}\text { (Kuancha et al., } \\
\text { 2017) }\end{array}$ & $\begin{array}{c}\text { Fermentable sugars production from } \\
\text { lignocellulosic materials } \\
\text { hydrolysis by thermophilic enzymes from } \\
\text { Bacillus subtilis J12 }\end{array}$ & $\begin{array}{l}\text { Artigo de pesquisa que apresenta alta eficiência na aplicação de Bacillus } \\
\text { subtilis para a produção de açúcares }\end{array}$ \\
\hline 53 & $\begin{array}{l}\text { (Agrawal et al., } \\
\text { 2017) }\end{array}$ & $\begin{array}{l}\text { Investigating the enzyme-lignin binding with } \\
\text { surfactants for improved saccharification of } \\
\text { pilot scale pretreated wheat straw }\end{array}$ & $\begin{array}{l}\text { Artigo de pesquisa que investigou uma enzima específica para a pré- } \\
\text { tratar palha de trigo }\end{array}$ \\
\hline 54 & $\begin{array}{l}\text { (A. M. H. Rocha et } \\
\text { al., 2017) }\end{array}$ & $\begin{array}{c}\text { Prospecção tecnológica do capim elefante e } \\
\text { sua relevância como matéria-prima para a } \\
\text { produção energética }\end{array}$ & $\begin{array}{l}\text { Artigo de revisão que apresenta a importância do CE para produção de } \\
\text { energias renováveis }\end{array}$ \\
\hline 55 & (Niemi et al., 2017) & $\begin{array}{c}\text { Production of sugars from grass silage after } \\
\text { steam explosion or soaking in aqueous } \\
\text { ammonia }\end{array}$ & $\begin{array}{l}\text { Artigo de pesquisa aplicando pré-tratamento ácido para a produção de } \\
\text { açúcar }\end{array}$ \\
\hline 56 & $\begin{array}{l}\text { (Renzaho et al., } \\
\text { 2017) }\end{array}$ & $\begin{array}{c}\text { Biofuel production and its impact on food } \\
\text { security in low and middle income countries: } \\
\text { Implications for the post-2015 sustainable } \\
\text { development goals }\end{array}$ & $\begin{array}{l}\text { Artigo de revisão que apresenta uma história do impacto da produção na } \\
\text { produção de biocombustíveis na produção de alimentos }\end{array}$ \\
\hline 57 & (Ko et al., 2017) & $\begin{array}{r}\text { Bioethanol production fr } \\
\text { grass with hed }\end{array}$ & $\begin{array}{r}\text { Artigo de pesquisa mostra a } 1 \\
\text { recupe }\end{array}$ \\
\hline 58 & (Merino et al., 2017) & $\begin{array}{l}\text { Screening of Ionic Liquids for Pretreatment of } \\
\text { Taiwan Grass in Q-Tube Minireactors for } \\
\text { Improving Bioethanol Production }\end{array}$ & $\begin{array}{c}\text { Artigo de pesquisa utilizando o Screening para o pré-tratamento do } \\
\text { capim Taiwan para a produção de bioetanol }\end{array}$ \\
\hline 59 & (Mithra et al., 2018) & $\begin{array}{l}\text { Comparison of ethanol yield from pretreated } \\
\text { lignocellulo-starch biomass under fed-batch } \\
\text { SHF or SSF modes }\end{array}$ & $\begin{array}{l}\text { Artigo de pesquisa onde foi comparado a produção de etanol a } \\
\text { estruturas lignocelulósicas entre hidrolise enzimática e ferment } \\
\text { sequência ou em conjunto }\end{array}$ \\
\hline 60 & $\begin{array}{l}\text { (Kumar \& Ghosh, } \\
\text { 2018) }\end{array}$ & $\begin{array}{l}\text { Sustainable bio-energy potential of perennial } \\
\text { energy grass from reclaimed coalmine spoil } \\
\text { (marginal sites) of India }\end{array}$ & $\begin{array}{l}\text { Artigo de pesquisa que apresentou resultados de uso de energia } \\
\text { sustentáveis para reduzir o uso de carvão }\end{array}$ \\
\hline 61 & $\begin{array}{l}\text { (Kumari \& Singh, } \\
\text { 2018) }\end{array}$ & $\begin{array}{l}\text { Pretreatment of lign } \\
\text { biofuel production }\end{array}$ & $\begin{array}{l}\text { Artigo de revisão } \\
\text { de resíduos }\end{array}$ \\
\hline 62 & $\begin{array}{c}\text { (Dhabhai et al., } \\
\text { 2018) }\end{array}$ & $\begin{array}{l}\text { Agricultural byproducts-based biosorbents for } \\
\text { purification of bioalcohols: a review }\end{array}$ & $\begin{array}{c}\text { Artigo de revisão do uso de produtos químicos para purificar ou limpar } \\
\text { os biocombustíveis }\end{array}$ \\
\hline 63 & $\begin{array}{c}\text { (Dhyani \& Bhaskar, } \\
\text { 2018) }\end{array}$ & $\begin{array}{c}\text { A comprehensive review on the pyrolysis of } \\
\text { lignocellulosic biomass }\end{array}$ & $\begin{array}{c}\text { Artigo de revisão sobre a utilização da pirolise química nas biomassas } \\
\text { lignocelulósicas }\end{array}$ \\
\hline 64 & (Kajina et al., 2018) & $\begin{array}{c}\text { Coupled effect of torrefaction and blending on } \\
\text { chemical and energy properties for combustion } \\
\text { of major open burned agriculture residues in } \\
\text { Thailand }\end{array}$ & $\begin{array}{l}\text { Artigo de pesquisa apresentando possibilidades de uso e energias } \\
\text { renováveis de diversas biomassas de alta disponibilidade na Tailândia }\end{array}$ \\
\hline 65 & $\begin{array}{l}\text { (Sawatdeenarunat et } \\
\text { al., 2018) }\end{array}$ & $\begin{array}{c}\text { Decentralized biorefinery for lignocellulosic } \\
\text { biomass: Integrating anaerobic digestion with } \\
\text { thermochemical conversion }\end{array}$ & $\begin{array}{l}\text { Artigo de pesquisa onde utilizou biorreatores para avaliar a digestão } \\
\text { anaeróbica para quantificar celulose e lignina }\end{array}$ \\
\hline 66 & (Zhang et al., 2019) & $\begin{array}{c}\text { An optimum combined hydrolysis factor } \\
\text { enhances hybrid Pennisetum pretreatment in } \\
\text { bio-conversion }\end{array}$ & $\begin{array}{l}\text { Artigo de pesquisa que apresentou resultados eficientes na combinação } \\
\text { de métodos para bioconversão de CE }\end{array}$ \\
\hline 67 & $\begin{array}{l}\text { (Mohapatra et al., } \\
\text { 2019) }\end{array}$ & $\begin{array}{c}\text { Engineering grass biomass for sustainable and } \\
\text { enhanced bioethanol production }\end{array}$ & $\begin{array}{c}\text { Artigo de revisão sobre a aplicação da engenharia genética na eficiência } \\
\text { da produção de bioenergia por biomassas }\end{array}$ \\
\hline 68 & (Farrokh et al., 2019) & $\begin{array}{l}\text { A thermogravimetric analysis of lignin char } \\
\text { combustion }\end{array}$ & $\begin{array}{r}\text { Artigo de pesquisa explicando so } \\
\text { combustão pa }\end{array}$ \\
\hline 69 & $\begin{array}{l}\text { (Gholizadeh et al., } \\
\text { 2019) }\end{array}$ & $\begin{array}{c}\text { A mini review of the specialties of the bio-oils } \\
\text { produced from pyrolysis of } 20 \text { different } \\
\text { biomasses }\end{array}$ & $\begin{array}{l}\text { Artigo de revisão apresentando as suas características químicas de } 20 \\
\text { diferentes biomassas quando produzido bio-óleo }\end{array}$ \\
\hline 70 & $\begin{array}{l}\text { (Narinthorn et al., } \\
\text { 2019) }\end{array}$ & $\begin{array}{l}\text { Alkaline and fungal pretreatments for } \\
\text { improving methane potential of Napier grass }\end{array}$ & $\begin{array}{l}\text { Artigo de pesquisa aplicando dois pré-tratamentos, alcalino e com fungo, } \\
\text { no CE para produção de metano }\end{array}$ \\
\hline 71 & $\begin{array}{l}\text { (Bonfiglio et al., } \\
\text { 2019) }\end{array}$ & $\begin{array}{l}\text { Pretreatment of switchgrass by steam explosion } \\
\text { in a semi-continuous pre-pilot reactor }\end{array}$ & $\begin{array}{c}\text { Artigo de pesquisa utilizando pré-tratamento a explosão em } \\
\text { semicondutores em reator }\end{array}$ \\
\hline 72 & (Dai et al., 2019) & $\begin{array}{l}\text { Integrated process of lignocellulosic biomass } \\
\text { torrefaction and pyrolysis for upgrading bio-oil } \\
\text { production: A state-of-the-art review }\end{array}$ & Artigo de revisão onde utilizou a pirólise para a produção de bio-óleo \\
\hline 73 & $\begin{array}{l}\text { (Camargos et al., } \\
\text { 2019) }\end{array}$ & $\begin{array}{c}\text { Experimentally designed corn biomass } \\
\text { fractionation to obtain lignin nanoparticles and } \\
\text { fermentable sugars }\end{array}$ & $\begin{array}{l}\text { Artigo de pesquisa sobre um planejamento experimental para } \\
\text { quantificação de lignina e celulose de biomassas }\end{array}$ \\
\hline 74 & $\begin{array}{l}\text { (Edem C. Bensah et } \\
\text { al., 2019) }\end{array}$ & $\begin{array}{c}\text { Alkali and glycerol pretreatment of West } \\
\text { African biomass for production of sugars and } \\
\text { ethanol }\end{array}$ & $\begin{array}{l}\text { Artigo de pesquisa utilizando pré-tratamento alcalino em diversos } \\
\text { materiais, mas o que se destacou foi o CE }\end{array}$ \\
\hline 75 & $\begin{array}{l}\text { (Yaashikaa et al., } \\
\text { 2019) }\end{array}$ & $\begin{array}{l}\text { Advances in production and application of } \\
\text { biochar from lignocellulosic feedstocks for } \\
\text { remediation of environmental pollutants }\end{array}$ & $\begin{array}{c}\text { Artigo de revisão produção de biogás de diversas fontes de biomassa } \\
\text { lignocelulósica }\end{array}$ \\
\hline
\end{tabular}


Research, Society and Development, v. 10, n. 15, e439101523302, 2021

(CC BY 4.0) | ISSN 2525-3409 | DOI: http://dx.doi.org/10.33448/rsd-v10i15.23302

\begin{tabular}{|c|c|c|c|}
\hline 76 & (Shilpi et al., 2019) & $\begin{array}{l}\text { Waste to watt: Anaerobic digestion of } \\
\text { wastewater irrigated biomass for energy and } \\
\text { fertiliser production }\end{array}$ & $\begin{array}{l}\text { Artigo de pesquisa sobre produção de energia com o uso de manejo de } \\
\text { irrigação e aplicação de fertilizantes }\end{array}$ \\
\hline 77 & (Kang et al., 2019) & $\begin{array}{l}\text { The effect of mechanical pretreatment on the } \\
\text { anaerobic digestion of Hybrid Pennisetum }\end{array}$ & $\begin{array}{l}\text { Artigo de pesquisa apresentando resultados de pré-tratamento mecânico } \\
\text { no CE }\end{array}$ \\
\hline 78 & $\begin{array}{l}\text { (Burman et al., } \\
\text { 2019) }\end{array}$ & $\begin{array}{l}\text { Lignocellulosic bioethanol production from } \\
\text { grasses pre-treated with acid mine drainage: } \\
\text { Modeling and comparison of SHF and SSF }\end{array}$ & $\begin{array}{c}\text { Artigo de pesquisa sobre aplicações de equações empíricas modelando a } \\
\text { concentração de glicose/etanol }\end{array}$ \\
\hline 79 & (Okolie et al., 2020) & $\begin{array}{l}\text { Chemistry and Specialty Industrial } \\
\text { Applications of Lignocellulosic Biomass }\end{array}$ & $\begin{array}{l}\text { Artigo de revisão que apresenta as potencialidades do uso de biomassas } \\
\text { lignocelulósicos para a produção de bioplásticos }\end{array}$ \\
\hline 80 & (Skiba et al., 2020) & $\begin{array}{l}\text { A technology for pilot production of bacterial } \\
\text { cellulose from oat hulls }\end{array}$ & $\begin{array}{c}\text { Artigo de pesquisa aplicando aveia para quantificar celulose por } \\
\text { processos que envolvem bactérias }\end{array}$ \\
\hline 81 & (Cai et al., & $\begin{array}{c}\text { Effects of dry explosion pretreatment on } \\
\text { physicochemical and fuel properties of hybrid } \\
\text { pennisetum (Pennisetum americanum } \times P . \\
\text { purpureum) } \\
\end{array}$ & $\begin{array}{l}\text { Artigo de pesquisa apresentado o pré-tratamento de explosão a seco para } \\
\text { converter biomassa de CE }\end{array}$ \\
\hline 82 & $\begin{array}{r}\text { (Brito da } \mathrm{S} \\
202 \\
\end{array}$ & $\begin{array}{l}\text { Assessment of energy production in full-sibling } \\
\text { families of elephant grass by mixed models }\end{array}$ & $\begin{array}{l}\text { Artigo de revisão que apresenta as potencialidades da família do CE para } \\
\text { produção de energias renováveis }\end{array}$ \\
\hline 83 & (Duarah et al., 2020) & $\begin{array}{c}\text { Technological advancement in the synthesis } \\
\text { and applications of lignin-based nanoparticles } \\
\text { derived from agro-industrial waste residues: } \\
\text { Areview }\end{array}$ & $\begin{array}{l}\text { Artigo de revisão sobre a aplicação de nanotecnologia para aplicar na } \\
\text { deslignificação }\end{array}$ \\
\hline 84 & $\begin{array}{l}\text { (Haldar \& Purkait, } \\
\text { 2020) }\end{array}$ & $\begin{array}{l}\text { Lignocellulosic conversion into value-added } \\
\text { products: A review }\end{array}$ & $\begin{array}{c}\text { Artigo de revisão sobre a importância da deslignificação para o uso de } \\
\text { energias renováveis }\end{array}$ \\
\hline 85 & $\begin{array}{l}\text { (Abraham et al., } \\
\text { 2020) }\end{array}$ & $\begin{array}{l}\text { Pretreatment strategies for enhanced biogas } \\
\text { production from lignocellulosic biomass }\end{array}$ & $\begin{array}{c}\text { Artigo de revisão mostrando a estratégia do uso do pré-tratamento na } \\
\text { biomassa para a produção de biogás }\end{array}$ \\
\hline 86 & (Roy et al., 2020) & $\begin{array}{l}\text { Recent advances of greener pretreatment } \\
\text { technologies of lignocellulose }\end{array}$ & $\begin{array}{l}\text { Artigo de revisão mostrando os avanços do uso da tecnologia do pré- } \\
\text { tratamento em materiais lignocelulósico }\end{array}$ \\
\hline
\end{tabular}

Fonte: Dados da pesquisa (fevereiro, 2021).

O Quadro 6 exibe a lista de todos os 86 artigos selecionados para a pesquisa e indica a contribuição de cada um.

Com base nos critérios adotados nesta revisão sistemática, foi possível identificar um avanço nas produções científicas relacionados a aplicação do pré-tratamento do capim-elefante como biomassa para a produção de bioetanol, reforçando que esta pesquisa é um trabalho de cunho inédito quanto a aplicação da lógica fuzzy no pré-tratamento alcalino do capim-elefante, o que reforça a sua importância.

A Figura 2, apresenta o número de publicações por ano obtidas na pesquisa, quando utilizado as Strings (Agriculture; Elephant grass; Pennisetum purpureum; Second-generation ethanol; Biofuels; Pretreatments; Sodium hidroxide; Lignin; Cellulosic; Lignocellulosic biomass e Fuzzy logic), nos modelos unidimensionais.

Figura 2. Publicações por ano.

Número de documentos publicados por ano

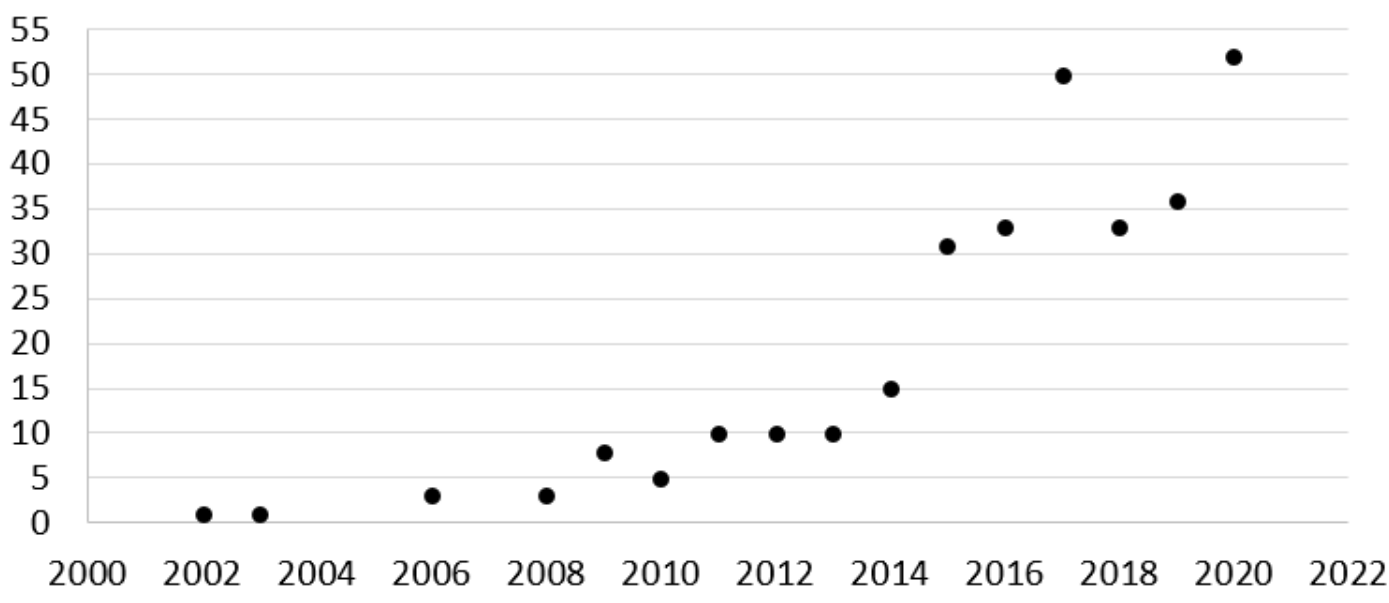

Fonte: Dados da pesquisa (fevereiro, 2021). 
A Figura 2, apresenta o número de publicações por ano, foram encontrados 395 documentos. Destes, 235 foram publicados nos últimos cinco anos (2015 a 2020), o que demonstra o avanço e relevância da temática abordada.

Na Figura 3 temos mais um resultado do software que considera as palavras-chave dos artigos selecionados na pesquisa.

Figura 3. Nuvem de palavras.

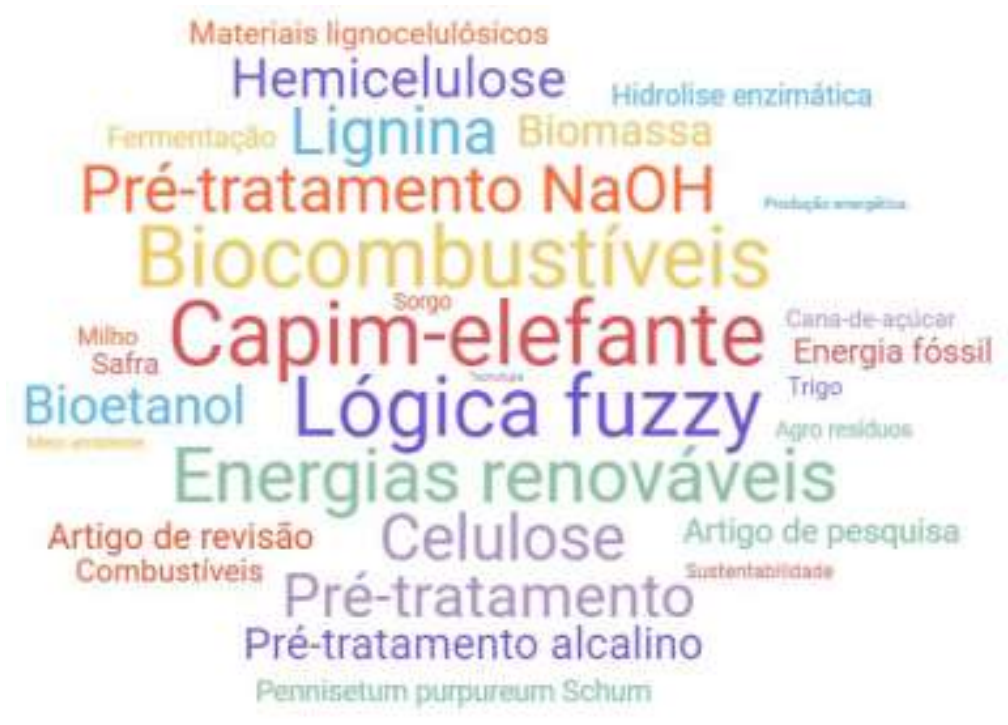

Fonte: Dados da pesquisa (fevereiro, 2021).

Na Figura 3 apresenta-se a nuvem de palavras gerada a partir das palavras-chave dos artigos selecionados, com destaque às palavras: Biocombustíveis, capim-elefante, lógica fuzzy, pré-tratamento $\mathrm{NaOH}$ e energias renováveis.

Ao analisar os documentos na íntegra, foi possível categorizar os documentos por aplicabilidade, sendo: Agriculture, Pennisetum purpureum, second-generation ethanol, biofuels, pretreatments, sodium hidroxide, lignin, cellulosic, lignocellulosic biomass e fuzzy logic, como demonstrado na Figura 4.

Figura 4. Número de documentos por aplicação.

Número de documentos por aplicação

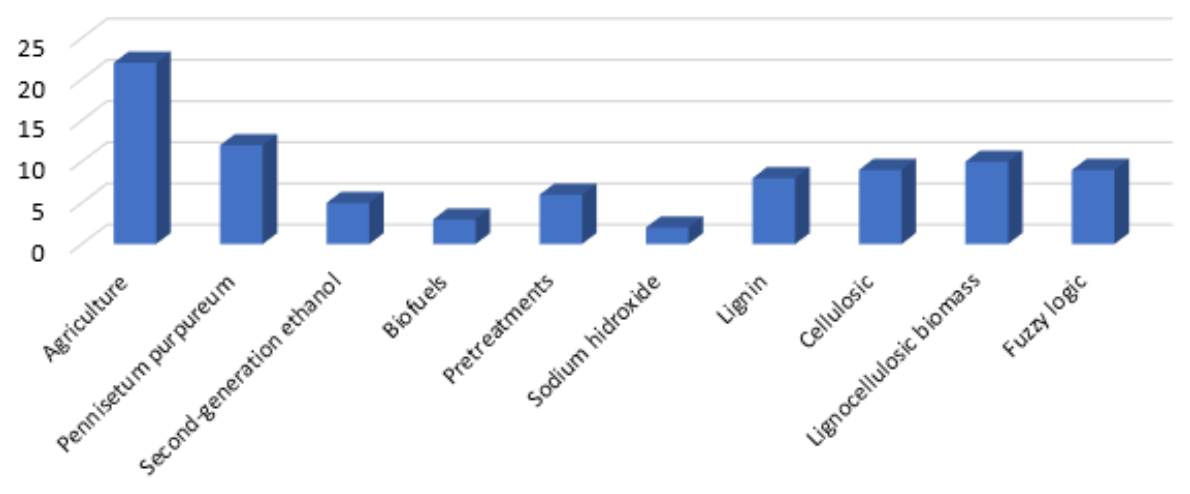

Fonte: Dados da pesquisa (fevereiro, 2021).

A Figura 4, demonstra a separação feita nos documentos elencados para a pesquisa, de forma a identificar as aplicações foco de cada um deles. Os focos mais relevantes foram encontrados, em maiores quantidades de artigos, para agriculture, Pennisetum purpureum, lignocellulosic biomass e cellulosic. 
Neste sentido, para o setor agroindustrial destaca-se os pontos agriculture, Pennisetum purpureum, lignocellulosic biomass e cellulosic, além do pretreatment e sodium hidroxide. (Zhang et al., 2019), avaliam que para obter uma alta eficiência na produção de etanol de segunda geração a partir do uso de biomassa de capim-elefante, o pré-tratamento é de grande relevância, pois ele desestrutura toda a lignina facilitando a ação do fungo para a fermentação e consequentemente a produção do bioetanol (Godinho et al., 2019).

Conforme visto na Figura 4, o sodium hidroxide apareceu relativamente baixa a quantidade de artigos, entretanto (Alonso, 2018) cita que o hidróxido de sódio é considerado um pré-tratamento alcalino com alta resposta na deslignificação da biomassa.

\section{Conclusão}

Com a realização da pesquisa utilizando a RBS, foi possível identificar diversas aplicações no uso da pré-tratamento alcalino com $\mathrm{NaOH}$ no capim-elefante para produção de bioetanol. Entretanto, reforça o ineditismo desta pesquisa no âmbito da aplicação da lógica fuzzy no pré-tratamento do capim-elefante, tanto para quantificar a celulose, a hemicelulose e a lignina, além da produção do bioetanol.

Dos 86 documentos analisados nesta pesquisa, 100\% foram de artigos de pesquisa quanto de artigo de revisão bibliográfica, o que demonstra uma relevância na academia quanto a pesquisa na linha de pesquisa quanto ao uso do capimelefante na produção do bioetanol e, da mesma forma, que as pesquisas sobre a aplicação de pré-tratamento nas biomassas vêm ganhando importância nos últimos anos, sendo cada vez mais estudada e desenvolvida por pesquisadores da área.

Apesar de não apresentar nenhum artigo com referência específica da utilização da lógica fuzzy no pré-tratamento alcalino do capim-elefante, isso abre espaço para novas pesquisas, onde pode-se utilizar as mesmas linhas de trabalho com a aplicação da lógica fuzzy como um modelo de otimização nas variáveis independentes nos processos de produção do bioetanol.

Portanto, para trabalhos futuros, recomenda-se uma análise mais aprofundada em cada documento identificado (86), o que poderá gerar novas pesquisas como, por exemplo, a aplicação da lógica fuzzy na produção de etanol de segunda geração no capim-elefante utilizando o pré-tratamento alcalino.

\section{Referências}

Abbasi, T., \& Abbasi, S. A. (2010). Biomass energy and the environmental impacts associated with its production and utilization. Renewable and Sustainable Energy Reviews, 14(3), 919-937. https://doi.org/10.1016/j.rser.2009.11.006

Abdelaziz, O. Y., Brink, D. P., Prothmann, J., Ravi, K., Sun, M., García-Hidalgo, J., Sandahl, M., Hulteberg, C. P., Turner, C., Lidén, G., \& Gorwa-Grauslund, M. F. (2016). Biological valorization of low molecular weight lignin. Biotechnology Advances, 34(8), 1318-1346. https://doi.org/10.1016/j.biotechadv.2016.10.001

Abraham, A., Mathew, A. K., Park, H., Choi, O., Sindhu, R., Parameswaran, B., Pandey, A., Park, J. H., \& Sang, B. I. (2020). Pretreatment strategies for enhanced biogas production from lignocellulosic biomass. Bioresource Technology, 301(October 2019), 122725. https://doi.org/10.1016/j.biortech.2019.122725

Aditiya, H. B., Mahlia, T. M. I., Chong, W. T., Nur, H., \& Sebayang, A. H. (2016). Second generation bioethanol production: A critical review. Renewable and Sustainable Energy Reviews, 66, 631-653. https://doi.org/10.1016/j.rser.2016.07.015

Agrawal, R., Satlewal, A., Kapoor, M., Mondal, S., \& Basu, B. (2017). Investigating the enzyme-lignin binding with surfactants for improved saccharification of pilot scale pretreated wheat straw. Bioresource Technology, 224, 411-418. https://doi.org/10.1016/j.biortech.2016.11.026

Ahmad, M. S., Mehmood, M. A., Liu, C. G., Tawab, A., Bai, F. W., Sakdaronnarong, C., Xu, J., Rahimuddin, S. A., \& Gull, M. (2018). Bioenergy potential of Wolffia arrhiza appraised through pyrolysis, kinetics, thermodynamics parameters and TG-FTIR-MS study of the evolved gases. Bioresource Technology, 253, 297-303. https://doi.org/10.1016/j.biortech.2018.01.033

Alonso, E. (2018). The role of supercritical fluids in the fractionation pretreatments of a wheat bran-based biorefinery. Journal of Supercritical Fluids, 133(September 2017), 603-614. https://doi.org/10.1016/j.supflu.2017.09.010

Antonopoulou, G., Gavala, H. N., Skiadas, I. V., \& Lyberatos, G. (2015). The Effect of Aqueous Ammonia Soaking Pretreatment on Methane Generation Using Different Lignocellulosic Biomasses. Waste and Biomass Valorization, 6(3), 281-291. https://doi.org/10.1007/s12649-015-9352-9 
Aquino, E. L. R. de, Neto, M. M., Bernardo, C. H. C., Morais, F. J. de O., \& Santos, P. S. B. dos. (2020). Ferramentas de manutenção preditiva de motores diesel: uma revisão bibliográfica sistemática. Research, Society and Development, 9(11), e57691110195. https://doi.org/10.33448/rsd-v9i11.10195

Bensah, Edem C., Kádár, Z., \& Mensah, M. Y. (2019). Alkali and glycerol pretreatment of West African biomass for production of sugars and ethanol. Bioresource Technology Reports, 6(February), 123-130. https://doi.org/10.1016/j.biteb.2019.02.013

Bensah, Edem Cudjoe, Kemausuor, F., Miezah, K., Kádár, Z., \& Mensah, M. (2015). African perspective on cellulosic ethanol production. Renewable and Sustainable Energy Reviews, 49, 1-11. https://doi.org/10.1016/j.rser.2015.04.059

Blois, H. D., Paris, E., Carvalho, M. P., \& Nunes, B. B. (2017). Silvicultura: Cenários Prospectivos para Geração de Energia Elétrica. Revista de Gestão Ambiental e Sustentabilidade, 6(1), 140-159. https://doi.org/10.5585/geas.v6i1.488

Bonfiglio, F., Cagno, M., Rey, F., Torres, M., Böthig, S., Menéndez, P., \& Mussatto, S. I. (2019). Pretreatment of switchgrass by steam explosion in a semicontinuous pre-pilot reactor. Biomass and Bioenergy, 121(November 2018), 41-47. https://doi.org/10.1016/j.biombioe.2018.12.013

Bracarense, J. C., Dos Santos, C. V., \& Mayerle, S. F. (2013). Tomada de decisão sob condições de risco e incerteza: uma aplicação da lógica fuzzy à bovinocultura de corte da região Serrana de Santa Catarina. Revista Teoria e Evidência Econômica, 19(41), 73-101. https://doi.org/10.5335/rtee.v0i41.3734

Brito da Silva, V., Daher, R. F., de Souza, Y. P., da Silva Menezes, B. R., Azevedo Santos, E., Souza Freitas, R., da Silva Oliveira, E., Francesconi Stida, W., \& Cassaro, S. (2020). Assessment of energy production in full-sibling families of elephant grass by mixed models. Renewable Energy, 146, 744-749. https://doi.org/10.1016/j.renene.2019.06.152

Burman, N. W., Sheridan, C. M., \& Harding, K. G. (2019). Lignocellulosic bioethanol production from grasses pre-treated with acid mine drainage: Modeling and comparison of SHF and SSF. Bioresource Technology Reports, 7(July), 100299. https://doi.org/10.1016/j.biteb.2019.100299

Cai, C., Wang, L., Wang, G., Hao, J., Bai, X., Wang, Z., \& Wang, D. (2020). Effects of dry explosion pretreatment on physicochemical and fuel properties of hybrid pennisetum (Pennisetum americanum $\times$ P. purpureum). Bioresource Technology, 297(November 2019), 122508. https://doi.org/10.1016/j.biortech.2019.122508

Camargos, C. H. M., Silva, R. A. P., Csordas, Y., Silva, L. L., \& Rezende, C. A. (2019). Experimentally designed corn biomass fractionation to obtain lignin nanoparticles and fermentable sugars. Industrial Crops and Products, 140(April), 111649. https://doi.org/10.1016/j.indcrop.2019.111649

Cardona, E., Rios, J., Peña, J., \& Rios, L. (2014). Effects of the pretreatment method on enzymatic hydrolysis and ethanol fermentability of the cellulosic fraction from elephant grass. Fuel, 118, 41-47. https://doi.org/10.1016/j.fuel.2013.10.055

Carvalho-Netto, O. V., Bressiani, J. A., Soriano, H. L., Fiori, C. S., Santos, J. M., Barbosa, G. V., Xavier, M. A., Landell, M. G., \& Pereira, G. A. (2014). The potential of the energy cane as the main biomass crop for the cellulosic industry. Chemical and Biological Technologies in Agriculture, 1-20. https://doi.org/10.1186/s40538-014-0020-2

Chandel, A. K., Singh, O. V., Chandrasekhar, G., Rao, L. V., \& Narasu, M. L. (2010). Key drivers influencing the commercialization of ethanol-based biorefineries. Journal of Commercial Biotechnology, 16(3), 239-257. https://doi.org/10.1057/jcb.2010.5

Charlton, A., Elias, R., Fish, S., Fowler, P., \& Gallagher, J. (2009). The biorefining opportunities in Wales: Understanding the scope for building a sustainable, biorenewable economy using plant biomass. Chemical Engineering Research and Design, 87(9), 1147-1161. https://doi.org/10.1016/j.cherd.2009.06.013

Coelho, Y. C. de M., Oliveira, E. M. de, \& Almeida, A. C. P. C. de. (2021). Discussões e tendências das teses e dissertações sobre formação de professores de ciências em espaços não formais: uma Revisão Bibliográfica Sistemática. Ensaio Pesquisa Em Educação Em Ciências (Belo Horizonte), 23, 1-18. https://doi.org/10.1590/1983-21172021230103

Coffin, A. W., Strickland, T. C., Anderson, W. F., Lamb, M. C., Lowrance, R. R., \& Smith, C. M. (2016). Potential for Production of Perennial Biofuel Feedstocks in Conservation Buffers on the Coastal Plain of Georgia, USA. Bioenergy Research, 9(2), 587-600. https://doi.org/10.1007/s12155-015-9700-4

Conforto, E. C., Amaral, D. C., \& Silva, S. L. Da. (2011). Roteiro para revisão bibliográfica sistemática: aplicação no desenvolvimento de produtos e gerenciamento de projetos. $8^{\circ}$ Congresso Brasileiro de Gestão de Desenvolviemnto de Produto - CNGDP 2011, 1-12. http://www.ufrgs.br/cbgdp2011/downloads/9149.pdf

Daher, R. F., Souza, L. B., Gravina, G. A., Machado, J. C., Ramos, H. C. C., Silva, V. Q. R., Menezes, B. R. S., Schneider, L. S. A., Oliveira, M. L. F., \& Gottardo, R. D. (2014). Use of elephant grass for energy production in Campos dos Goytacazes-RJ, Brazil. Genetics and Molecular Research, 13(4), 1089810908. https://doi.org/10.4238/2014.December.19.11

Dai, L., Wang, Y., Liu, Y., Ruan, R., He, C., Yu, Z., Jiang, L., Zeng, Z., \& Tian, X. (2019). Integrated process of lignocellulosic biomass torrefaction and pyrolysis for upgrading bio-oil production: A state-of-the-art review. Renewable and Sustainable Energy Reviews, 107(February), 20-36. https://doi.org/10.1016/j.rser.2019.02.015

Del Río, J. C., Lino, A. G., Colodette, J. L., Lima, C. F., Gutiérrez, A., Martínez, Á. T., Lu, F., Ralph, J., \& Rencoret, J. (2015). Differences in the chemical structure of the lignins from sugarcane bagasse and straw. Biomass and Bioenergy, 81, 322-338. https://doi.org/10.1016/j.biombioe.2015.07.006

Demain, A. L. (2009). Biosolutions to the energy problem. Journal of Industrial Microbiology and Biotechnology, 36(3), 319-332. https://doi.org/10.1007/s10295-008-0521-8

Dhabhai, R., Niu, C. H., \& Dalai, A. K. (2018). Agricultural byproducts-based biosorbents for purification of bioalcohols: A review. Bioresources and Bioprocessing, 5(1). https://doi.org/10.1186/s40643-018-0223-7

Dhyani, V., \& Bhaskar, T. (2018). A comprehensive review on the pyrolysis of lignocellulosic biomass. Renewable Energy, 129, 695-716. https://doi.org/10.1016/j.renene.2017.04.035 
Duarah, P., Haldar, D., \& Purkait, M. K. (2020). Technological advancement in the synthesis and applications of lignin-based nanoparticles derived from agroindustrial waste residues: A review. International Journal of Biological Macromolecules, 163, 1828-1843. https://doi.org/10.1016/j.ijbiomac.2020.09.076

Duku, M. H., Gu, S., \& Hagan, E. Ben. (2011). A comprehensive review of biomass resources and biofuels potential in Ghana. Renewable and Sustainable Energy Reviews, 15(1), 404-415. https://doi.org/10.1016/j.rser.2010.09.033

Dutra, E. D., Santos, F. A., Alencar, B. R. A., Reis, A. L. S., de Souza, R. de F. R., Aquino, K. A. da S., Morais, M. A., \& Menezes, R. S. C. (2018). Alkaline hydrogen peroxide pretreatment of lignocellulosic biomass: status and perspectives. Biomass Conversion and Biorefinery, 8(1), 225-234. https://doi.org/10.1007/s13399-017-0277-3

Eusébio, C., \& João, M. (2020). Attitudes towards people with disabilities: A systematic literature review | Atitudes em relação às pessoas com deficiência: Uma revisão sistemática da literatura. Revista Brasileira de Educacao Especial, 26(4), 689-710.

Farrokh, N. T., Suopajärvi, H., Sulasalmi, P., \& Fabritius, T. (2019). A thermogravimetric analysis of lignin char combustion. Energy Procedia, 158, 1241-1248. https://doi.org/10.1016/j.egypro.2019.01.413

Fontoura, C. F., Brandão, L. E., \& Gomes, L. L. (2015). Elephant grass biorefineries: Towards a cleaner Brazilian energy matrix? Journal of Cleaner Production, 96, 85-93. https://doi.org/10.1016/j.jclepro.2014.02.062

Furlong, V. B., Corrêa, L. J., Giordano, R. C., \& Ribeiro, M. P. A. (2019). Fuzzy-enhanced modeling of lignocellulosic biomass enzymatic saccharification. Energies, 12(11). https://doi.org/10.3390/en12112110

Galvão, C. M., Sawada, N. O., \& Trevizan, M. A. (2004). Revisão sistemática: recurso que proporciona a incorporação das evidências na prática da enfermagem. Revista Latino-Americana de Enfermagem, 12(3), 549-556. https://doi.org/10.1590/s0104-11692004000300014

Gholizadeh, M., Hu, X., \& Liu, Q. (2019). A mini review of the specialties of the bio-oils produced from pyrolysis of 20 different biomasses. Renewable and Sustainable Energy Reviews, 114(August), 109313. https://doi.org/10.1016/j.rser.2019.109313

Godinho, E. Z., Perin, A. A., Baumgartner, T. R. da S., \& Hasan, S. D. M. (2019). Pré-tratamento hidrotérmico alcalino e alcalino-oxidativo sobre os teores de celulose e lignina em biomassa de capim elefante BRS Capiaçu. Journal of Bioenergy and Food Science, 6(3), 51-65. https://doi.org/10.18067/jbfs.v6i3.263

Gomes, B. L., Martelli, F. H., \& Silva, W. T. L. da. (2013). Caracterização físico-química e morfológica de biomassa de capim- elefante,capimmombaça.brachiaria, sorgo-embrapa e bagaço de cana-de-açucar. III Symposium on Agricultural and Agroindustrial Waste Management, 4.

Gunaseelan, V. N. (1997). Anaerobic digestion of biomass for methane production: A review. Biomass and Bioenergy, 13(1-2), 83-114. https://doi.org/10.1016/S0961-9534(97)00020-2

Gupta, A., \& Verma, J. P. (2015). Sustainable bio-ethanol production from agro-residues: A review. Renewable and Sustainable Energy Reviews, 41, 550-567. https://doi.org/10.1016/j.rser.2014.08.032

Gutierrez, E. C., Xia, A., \& Murphy, J. D. (2016). Can slurry biogas systems be cost effective without subsidy in Mexico? Renewable Energy, 95, 22-30. https://doi.org/10.1016/j.renene.2016.03.096

Haldar, D., \& Purkait, M. K. (2020). Lignocellulosic conversion into value-added products: A review. Process Biochemistry, 89(October 2019), 110-133. https://doi.org/10.1016/j.procbio.2019.10.001

He, C. R., Kuo, Y. Y., \& Li, S. Y. (2017). Lignocellulosic butanol production from Napier grass using semi-simultaneous saccharification fermentation. Bioresource Technology, 231, 101-108. https://doi.org/10.1016/j.biortech.2017.01.039

Ho, C. Y., Chang, J. J., Lee, S. C., Chin, T. Y., Shih, M. C., Li, W. H., \& Huang, C. C. (2012). Development of cellulosic ethanol production process via coculturing of artificial cellulosomal Bacillus and kefir yeast. Applied Energy, 100, 27-32. https://doi.org/10.1016/j.apenergy.2012.03.016

Ji, X., \& Long, X. (2016). A review of the ecological and socioeconomic effects of biofuel and energy policy recommendations. Renewable and Sustainable Energy Reviews, 61, 41-52. https://doi.org/10.1016/j.rser.2016.03.026

Jin, S., Zhang, G., Zhang, P., Fan, S., \& Li, F. (2015). High-pressure homogenization pretreatment of four different lignocellulosic biomass for enhancing enzymatic digestibility. Bioresource Technology, 181, 270-274. https://doi.org/10.1016/j.biortech.2015.01.069

Johansson, S., \& Rydberg, T. (2017). Is an increased use of biofuels the road to sustainability?: Consequences of the methodological approach. European Physical Journal Plus, 132(2), 1-14. https://doi.org/10.1140/epjp/i2017-11333-0

Kajina, W., Rousset, P., Chen, W. H., Sornpitak, T., \& Commandré, J. M. (2018). Coupled effect of torrefaction and blending on chemical and energy properties for combustion of major open burned agriculture residues in Thailand. Renewable Energy, 118, 113-121. https://doi.org/10.1016/j.renene.2017.11.006

Kang, X., Zhang, Y., Song, B., Sun, Y., Li, L., He, Y., Kong, X., Luo, X., \& Yuan, Z. (2019). The effect of mechanical pretre atment on the anaerobic digestion of Hybrid Pennisetum. Fuel, 252(April), 469-474. https://doi.org/10.1016/j.fuel.2019.04.134

Karagöz, P., Rocha, I. V., Özkan, M., \& Angelidaki, I. (2012). Alkaline peroxide pretreatment of rapeseed straw for enhancing bioethanol production by Same Vessel Saccharification and Co-Fermentation. Bioresource Technology, 104, 349-357. https://doi.org/10.1016/j.biortech.2011.10.075

Kim, J. S., Lee, Y. Y., \& Kim, T. H. (2016a). A review on alkaline pretreatment technology for bioconversion of lignocellulosic biomass. Bioresource Technology, 199, 42-48. https://doi.org/10.1016/j.biortech.2015.08.085

Kim, J. S., Lee, Y. Y., \& Kim, T. H. (2016b). A review on alkaline pretreatment technology for bioconversion of lignocellulosic biomass. Bioresource Technology, 199, 42-48. https://doi.org/10.1016/j.biortech.2015.08.085 
Knoll, J. E., Johnson, J. M., Lee, R. D., \& Anderson, W. F. (2014). Harvest Management of 'Tifton 85' Bermudagrass for Cellulosic Ethanol Production. Bioenergy Research, 7(4), 1112-1119. https://doi.org/10.1007/s12155-014-9449-1

Ko, C. H., Yu, F. C., Chang, F. C., Yang, B. Y., Chen, W. H., Hwang, W. S., \& Tu, T. C. (2017). Bioethanol production from recovered napier grass with heavy metals. Journal of Environmental Management, 203, 1005-1010. https://doi.org/10.1016/j.jenvman.2017.04.049

Kuancha, C., Sukklang, S., Detvisitsakun, C., Chanton, S., \& Apiraksakorn, J. (2017). Fermentable sugars production from lignocellulosic materials hydrolysis by thermophilic enzymes from Bacillus subtilis J12. Energy Procedia, 138, 151-156. https://doi.org/10.1016/j.egypro.2017.10.084

Kumar, S., \& Ghosh, P. (2018). Sustainable bio-energy potential of perennial energy grass from reclaimed coalmine spoil (marginal sites) of India. Renewable Energy, 123, 475-485. https://doi.org/10.1016/j.renene.2018.02.054

Kumari, D., \& Singh, R. (2018). Pretreatment of lignocellulosic wastes for biofuel production: A critical review. Renewable and Sustainable Energy Reviews, 90(May 2017), 877-891. https://doi.org/10.1016/j.rser.2018.03.111

Lima, M. A., Gomez, L. D., Steele-King, C. G., Simister, R., Bernardinelli, O. D., Carvalho, M. A., Rezende, C. A., Labate, C. A., Deazevedo, E. R., McQueenMason, S. J., \& Polikarpov, I. (2014). Evaluating the composition and processing potential of novel sources of Brazilian biomass for sustainable biorenewables production. Biotechnology for Biofuels, 7(1), 1-19. https://doi.org/10.1186/1754-6834-7-10

López-Bellido, L., Wery, J., \& López-Bellido, R. J. (2014). Energy crops: Prospects in the context of sustainable agriculture. European Journal of Agronomy, 60,1-12. https://doi.org/10.1016/j.eja.2014.07.001

Lucas, C. A. (2011). Uma Introdução á Lógica Fuzzy. Revista Eletrônica de Sistemas de Informação e de Gestão Tecnológica, 1(1), 17-28.

Manisha, \& Yadav, S. K. (2017). Technological advances and applications of hydrolytic enzymes for valorization of lignocellulosic biomass. Bioresource Technology, 245, 1727-1739. https://doi.org/10.1016/j.biortech.2017.05.066

Maranzato, F. P., \& Salerno, M. S. (2018). Integration between research and development: A dynamic capabilities perspective. RAE - Revista de Administracao de Empresas, 58(5), 460-474. https://doi.org/10.1590/S0034-759020180503

Massi, L., De Souza, B. N., Sgarbosa, E. C., \& Colturato, A. R. (2019). Historical-critical pedagogy incorporation in science education: A dialectic critical analysis of a systematic bibliographic review. Investigacoes Em Ensino de Ciencias, 24(2), 212-255. https://doi.org/10.22600/1518-8795.ienci2019v24n2p212

Menegol, D., Scholl, A. L., Fontana, R. C., Dillon, A. J. P., \& Camassola, M. (2014). Increased release of fermentable sugars from elephant grass by enzymatic hydrolysis in the presence of surfactants. Energy Conversion and Management, 88, 1252-1256. https://doi.org/10.1016/j.enconman.2014.02.071

Merino, O., Almazán, V., Martínez-Palou, R., \& Aburto, J. (2017). Screening of Ionic Liquids for Pretreatment of Taiwan Grass in Q-Tube Minireactors for Improving Bioethanol Production. Waste and Biomass Valorization, 8(3), 733-742. https://doi.org/10.1007/s12649-016-9612-3

Minmunin, J., Limpitipanich, P., \& Promwungkwa, A. (2015). Delignification of Elephant Grass for Production of Cellulosic Intermediate. Energy Procedia, 79, 220-225. https://doi.org/10.1016/j.egypro.2015.11.468

Mithra, M. G., Jeeva, M. L., Sajeev, M. S., \& Padmaja, G. (2018). Comparison of ethanol yield from pretreated lignocellulo-starch biomass under fed-batch SHF or SSF modes. Heliyon, 4(10), e00885. https://doi.org/10.1016/j.heliyon.2018.e00885

MME, M. de M. e E. (2020). BALANÇO ENERGÉTICO NACIONAL. In Empresa de Pesquisa Energética- EPE (p. 264).

Mohapatra, S., Mishra, C., Behera, S. S., \& Thatoi, H. (2017). Application of pretreatment, fermentation and molecular techniques for enhancing bioethanol production from grass biomass - A review. Renewable and Sustainable Energy Reviews, 78(November 2016), 1007-1032. https://doi.org/10.1016/j.rser.2017.05.026

Mohapatra, S., Mishra, S. S., Bhalla, P., \& Thatoi, H. (2019). Engineering grass biomass for sustainable and enhanced bioethanol production. Planta, 250(2), 395-412. https://doi.org/10.1007/s00425-019-03218-y

Narinthorn, R., Choorit, W., \& Chisti, Y. (2019). Alkaline and fungal pretreatments for improving methane potential of Napier grass. Biomass and Bioenergy, 127(April), 105262. https://doi.org/10.1016/j.biombioe.2019.105262

Nassef, A. M., Rezk, H., Abdelkareem, M. A., Alaswad, A., \& Olabi, A. (2019). Application of fuzzy modelling and Particle Swarm Optimization to enhance lipid extraction from microalgae. Sustainable Energy Technologies and Assessments, 35(January), 73-79. https://doi.org/10.1016/j.seta.2019.06.003

Niemi, P., Pihlajaniemi, V., Rinne, M., \& Siika-aho, M. (2017). Production of sugars from grass silage after steam explosion or soaking in aqueous ammonia. Industrial Crops and Products, 98, 93-99. https://doi.org/10.1016/j.indcrop.2017.01.022

Ohimain, E. I. (2013). A review of the Nigerian biofuel policy and incentives (2007). Renewable and Sustainable Energy Reviews, 22, 246-256. https://doi.org/10.1016/j.rser.2013.01.037

Okolie, J. A., Nanda, S., Dalai, A. K., \& Kozinski, J. A. (2020). Chemistry and Specialty Industrial Applications of Lignocellulosic Biomass. Waste and Biomass Valorization, 12, 2145-2169. https://doi.org/10.1007/s12649-020-01123-0

Paula, P. R. P., Júnior, A. P. N., de Souza, W. L., de Abreu, M. J. I., Teixeira, R. M. A., Cappelle, E. R., \& Tavares, V. B. (2020). Composição bromatológica da silagem de capim- elefante BRS Capiaçu com inclusão fubá de milho Chemical composition of BRS Capiaçu elephant grass silage with cornmeal inclusion. Composición química del ensilaje de pasto elefante BRS Capiaçu con inclusión. Pubvet, 14, 148. https://doi.org/10.31533/pubvet.v14n10a680.1-11

Perlatti, B., Forim, M. R., \& Zuin, V. G. (2014). Green chemistry, sustainable agriculture and processing systems: a Brazilian overview. Chemical and Biological Technologies in Agriculture, 1(5), 1-9. https://doi.org/10.1186/s40538-014-0005-1

Phitsuwan, P., Charupongrat, S., Klednark, R., \& Ratanakhanokchai, K. (2015). Structural features and enzymatic digestibility of Napier grass fibre treated with aqueous ammonia. Journal of Industrial and Engineering Chemistry, 32, 360-364. https://doi.org/10.1016/j.jiec.2015.09.006 
Plácido, J., Imam, T., \& Capareda, S. (2013). Evaluation of ligninolytic enzymes, ultrasonication and liquid hot water as pretreatments for bioethanol production from cotton gin trash. Bioresource Technology, 139, 203-208. https://doi.org/10.1016/j.biortech.2013.04.012

Puri, M., Abraham, R. E., \& Barrow, C. J. (2012). Biofuel production: Prospects, challenges and feedstock in Australia. Renewable and Sustainable Energy Reviews, 16(8), 6022-6031. https://doi.org/10.1016/j.rser.2012.06.025

Puspawati, S., Wagiman, Ainuri, M., Nugraha, D. A., \& Haslianti. (2015). The Production of Bioethanol Fermentation Substrate from Eucheuma cottonii Seaweed through Hydrolysis by Cellulose Enzyme. Agriculture and Agricultural Science Procedia, 3, 200-205. https://doi.org/10.1016/j.aaspro.2015.01.039

Rabemanolontsoa, H., \& Saka, S. (2016). Various pretreatments of lignocellulosics. Bioresource Technology, 199, 83-91. https://doi.org/10.1016/j.biortech.2015.08.029

Rambo, M. K. D., Schmidt, F. L., \& Ferreira, M. M. C. (2015). Analysis of the lignocellulosic components of biomass residues for biorefinery opportunities. Talanta, 144, 696-703. https://doi.org/10.1016/j.talanta.2015.06.045

Ren, N. Q., Zhao, L., Chen, C., Guo, W. Q., \& Cao, G. L. (2016). A review on bioconversion of lignocellulosic biomass to H2: Key challenges and new insights. Bioresource Technology, 215, 92-99. https://doi.org/10.1016/j.biortech.2016.03.124

Renzaho, A. M. N., Kamara, J. K., \& Toole, M. (2017). Biofuel production and its impact on food security in low and middle income countries: Implications for the post-2015 sustainable development goals. Renewable and Sustainable Energy Reviews, 78(January), 503-516. https://doi.org/10.1016/j.rser.2017.04.072

Rocha, A. M. H., Silva, M. S., Fernandes, F. M., Paulillo, L. C. M. S., \& Torres, E. A. (2017). Prospecção tecnológica do capim elefante e sua relevância como matéria-prima para a produção energética. Revista Em Agronegocio e Meio Ambiente, 10(2), 475-499. https://doi.org/10.17765/2176-9168.2017v10n2p475499

Rocha, J. R. do A. S. de C., Machado, J. C., Carneiro, P. C. S., Carneiro, J. da C., Resende, M. D. V., Lédo, F. J. da S., \& Carneiro, J. E. de S. (2017). Bioenergetic potential and genetic diversity of elephantgrass via morpho-agronomic and biomass quality traits. Industrial Crops and Products, 95, 485-492. https://doi.org/10.1016/j.indcrop.2016.10.060

Roy, R., Rahman, M. S., \& Raynie, D. E. (2020). Recent advances of greener pretreatment technologies of lignocellulose. Current Research in Green and Sustainable Chemistry, 3(August), 100035. https://doi.org/10.1016/j.crgsc.2020.100035

Saidur, R., Abdelaziz, E. A., Demirbas, A., Hossain, M. S., \& Mekhilef, S. (2011). A review on biomass as a fuel for boilers. Renewable and Sustainable Energy Reviews, 15(5), 2262-2289. https://doi.org/10.1016/j.rser.2011.02.015

Sánchez, C. (2009). Lignocellulosic residues: Biodegradation and bioconversion by fungi. Biotechnology Advances, 27(2), 185-194. https://doi.org/10.1016/j.biotechadv.2008.11.001

Sawatdeenarunat, C., Nam, H., Adhikari, S., Sung, S., \& Khanal, S. K. (2018). Decentralized biorefinery for lignocellulosic biomass: Integrating anaerobic digestion with thermochemical conversion. Bioresource Technology, 250(November 2017), 140-147. https://doi.org/10.1016/j.biortech.2017.11.020

Scholl, A. L., Menegol, D., Pitarelo, A. P., Fontana, R. C., Filho, A. Z., Ramos, L. P., Dillon, A. J. P., \& Camassola, M. (2015a). Elephant grass pretreated by steam explosion for inducing secretion of cellulases and xylanases by Penicillium echinulatum S1M29 solid-state cultivation. Industrial Crops and Products, 77 , 97-107. https://doi.org/10.1016/j.indcrop.2015.08.051

Scholl, A. L., Menegol, D., Pitarelo, A. P., Fontana, R. C., Filho, A. Z., Ramos, L. P., Dillon, A. J. P., \& Camassola, M. (2015b). Ethanol production from sugars obtained during enzymatic hydrolysis of elephant grass (Pennisetum purpureum, Schum.) pretreated by steam explosion. Bioresource Technology, 192, 228237. https://doi.org/10.1016/j.biortech.2015.05.065

Shilpi, S., Lamb, D., Bolan, N., Seshadri, B., Choppala, G., \& Naidu, R. (2019). Waste to watt: Anaerobic digestion of wastewater irrigated biomass for energy and fertiliser production. Journal of Environmental Management, 239(August 2018), 73-83. https://doi.org/10.1016/j.jenvman.2019.02.122

Singh, S. K., \& Dhepe, P. L. (2016). Isolation of lignin by organosolv process from different varieties of rice husk: Understanding their physical and chemical properties. Bioresource Technology, 221, 310-317. https://doi.org/10.1016/j.biortech.2016.09.042

Skiba, E. A., Budaeva, V. V., Ovchinnikova, E. V., Gladysheva, E. K., Kashcheyeva, E. I., Pavlov, I. N., \& Sakovich, G. V. (2020). A technology for pilot production of bacterial cellulose from oat hulls. Chemical Engineering Journal, 383(September 2019), 123128. https://doi.org/10.1016/j.cej.2019.123128

Smith, A. L., Klenk, N., Wood, S., Hewitt, N., Henriques, I., Yan, N., \& Bazely, D. R. (2013). Second generation biofuels and bioinvasions: An evaluation of invasive risks and policy responses in the United States and Canada. Renewable and Sustainable Energy Reviews, 27 , 30-42. https://doi.org/10.1016/j.rser.2013.06.013

Surendra, K. C., \& Khanal, S. K. (2015). Effects of crop maturity and size reduction on digestibility and methane yield of dedicated energy crop. Bioresource Technology, 178, 187-193. https://doi.org/10.1016/j.biortech.2014.09.055

Takara, D., \& Khanal, S. K. (2011). Green processing of tropical banagrass into biofuel and biobased products: An innovative biorefinery approach. Bioresource Technology, 102(2), 1587-1592. https://doi.org/10.1016/j.biortech.2010.08.106

Takara, D., \& Khanal, S. K. (2015). Characterizing compositional changes of Napier grass at different stages of growth for biofuel and biobased products potential. Bioresource Technology, 188, 103-108. https://doi.org/10.1016/j.biortech.2015.01.114

Timilsena, Y. P., Abeywickrama, C. J., Rakshit, S. K., \& Brosse, N. (2013). Effect of different pretreatments on delignification pattern and enzymatic hydrolysability of miscanthus, oil palm biomass and typha grass. Bioresource Technology, 135, 82-88. https://doi.org/10.1016/j.biortech.2012.09.010

Ullah, K., Kumar Sharma, V., Dhingra, S., Braccio, G., Ahmad, M., \& Sofia, S. (2015). Assessing the lignocellulosic biomass resources potential in developing countries: A critical review. Renewable and Sustainable Energy Reviews, 51, 682-698. https://doi.org/10.1016/j.rser.2015.06.044 
Research, Society and Development, v. 10, n. 15, e439101523302, 2021

(CC BY 4.0) | ISSN 2525-3409 | DOI: http://dx.doi.org/10.33448/rsd-v10i15.23302

Varfolomeev, S. D., Moiseev, I. I., \& Myasoedov, B. F. (2009). Energy carriers from renewable sources: Chemical aspects. Herald of the Russian Academy of Sciences, 79(4), 334-344. https://doi.org/10.1134/S1019331609040030

Vasconcelos de Almeida Sá, Y., \& Chiun Wen, T. (2019). Artificial Intelligence (FUZZY Logic) for local safety stock forecasting in multinational companies. Revista Gestão Da Produção Operações e Sistemas, 14(4), 1-10. https://doi.org/10.15675/gepros.v14i4.2661

Wen, B., Yuan, X., Li, Q. X., Liu, J., Ren, J., Wang, X., \& Cui, Z. (2015). Comparison and evaluation of concurrent saccharification and anaerobic digestion of Napier grass after pretreatment by three microbial consortia. Bioresource Technology, 175, 102-111. https://doi.org/10.1016/j.biortech.2014.10.043

Wu, M., Pang, J., Lu, F., Zhang, X., Che, L., Xu, F., \& Sun, R. (2013). Application of new expansion pretreatment method on agricultural waste. Part I: Influence of pretreatment on the properties of lignin. Industrial Crops and Products, 50, 887-895. https://doi.org/10.1016/j.indcrop.2013.08.047

Xie, X. M., Zhang, X. Q., Dong, Z. X., \& Guo, H. R. (2011). Dynamic changes of lignin contents of MT-1 elephant grass and its closely related cultivars. Biomass and Bioenergy, 35(5), 1732-1738. https://doi.org/10.1016/j.biombioe.2011.01.018

Yaashikaa, P. R., Senthil Kumar, P., Varjani, S. J., \& Saravanan, A. (2019). Advances in production and application of biochar from lignocellulosic feedstocks for remediation of environmental pollutants. Bioresource Technology, 292(July), 122030. https://doi.org/10.1016/j.biortech.2019.122030

Yasuda, M., Miura, A., Shiragami, T., Matsumoto, J., Kamei, I., Ishii, Y., \& Ohta, K. (2012). Ethanol production from non-pretreated napiergrass through a simultaneous saccharification and fermentation process followed by a pentose fermentation with Escherichia coli KO11. Journal of Bioscience and Bioengineering, 114(2), 188-192. https://doi.org/10.1016/j.jbiosc.2012.03.011

Yasuda, M., Nagai, H., Takeo, K., Ishii, Y., \& Ohta, K. (2014). Bio-ethanol production through simultaneous saccharification and co-fermentation (SSCF) of a low-moisture anhydrous ammonia (LMAA)-pretreated napiegrass (Pennisetum purpureum Schumach). SpringerPlus, 3(1). https://doi.org/10.1186/2193-18013-333

Zabed, H., Sahu, J. N., Boyce, A. N., \& Faruq, G. (2016). Fuel ethanol production from lignocellulosic biomass: An overview on feedstocks and technological approaches. Renewable and Sustainable Energy Reviews, 66, 751-774. https://doi.org/10.1016/j.rser.2016.08.038

Zhang, J., Qu, X., Zhu, G., Zhang, X., \& Tan, T. (2019). An optimum combined hydrolysis factor enhances hybrid Pennisetum pretreatment in bio-conversion. Cellulose, 26(15), 8439-8451. https://doi.org/10.1007/s10570-019-02561-3 